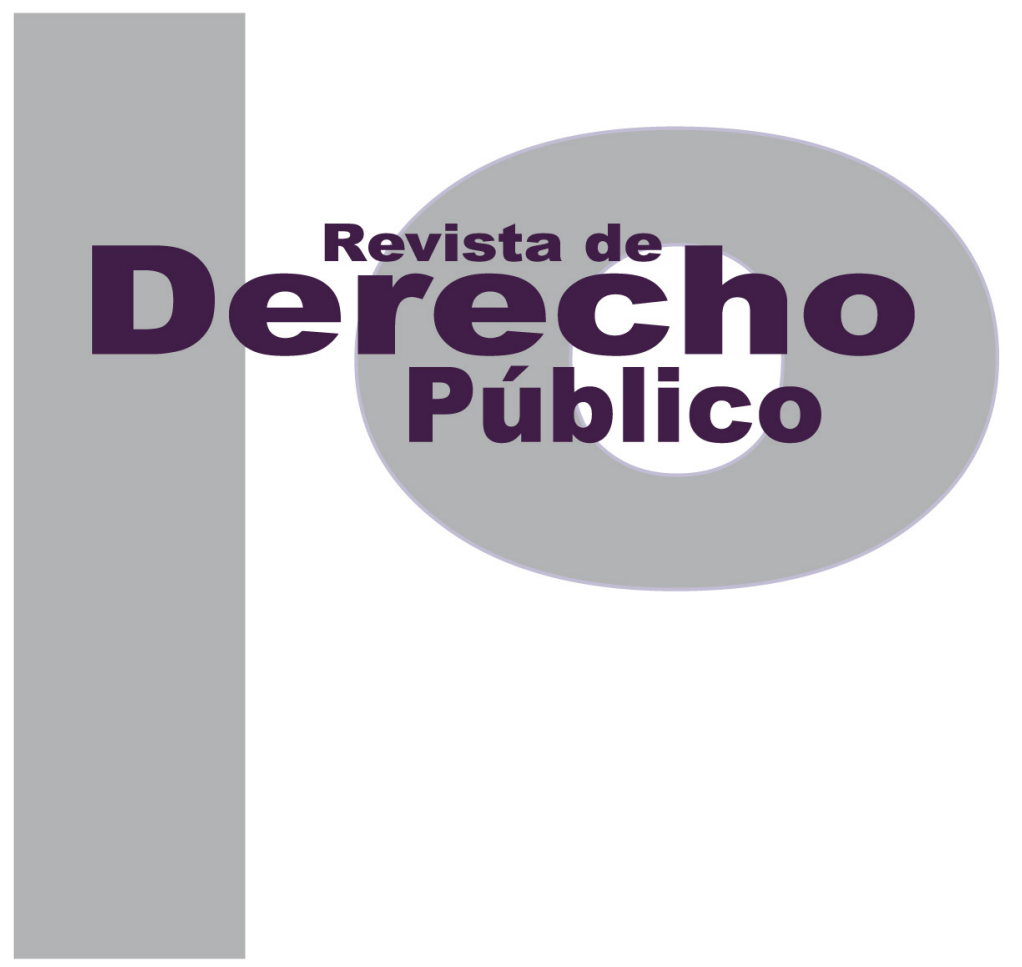

\title{
DILEMAS SOBRE LA RELACIÓN ENTRE DERECHO Y MORAL. A PROPÓSITO DE LA SENTENCIA C-404 DE 1998, DE LA CORTE CONSTITUCIONAL DE COLOMBIA
}

\author{
HENRIK LÓPEZ STERUP \\ Documento de reflexión no derivado de investigación
}

DOI: http://dx.doi.org/10.15425/redepub.36.2016.03

Universidad de los Andes

Facultad de Derecho

Rev. derecho publico No. 36

enero - junio de 2016. e-ISSN 1909-7778 


\section{Dilemas sobre la relación entre derecho y moral. A propósito de la Sentencia C-404 de 1998, de la Corte Constitucional de Colombia}

\section{Resumen}

La relación entre derecho y moral es un debate constante en la teoría del derecho. Usualmente se considera la cuestión de las normas jurídicas injustas. Pocas veces se estudia esta relación a partir de normas jurídicas que únicamente persiguen fines morales. El objetivo de este documento es el estudio de dicha relación, con ocasión del debate que se dio en el caso de la Sentencia C-404 de 1998 de la Corte Constitucional de Colombia. Se busca mostrar las dificultades a las que se enfrenta el juez constitucional al justificar la compatibilidad de reglas morales con la Constitución y, a la vez, avanzar alternativas ante las soluciones propuestas por la Corte. Se demuestra que el juez constitucional termina por incorporar la regla moral sin someterla a un análisis jurídico. La metodología parte del análisis de la argumentación y la reflexión conceptual.

Palabras clave: moral, derecho, relación moral y derecho, incesto, constitucionalismo, positivismo, argumentación jurídica.

\section{Dilemmas about the relationship between law and morals. An inquiry based on Colombia's Constitutional Court Case C-404/98}

Abstract

The relation between law and morals is a constant debate in jurisprudence. Usually the issue is considered from the case of unjust norms. Few studies deal with the case of legal rules that only pursues moral purposes. The aim of this document is to study this relation, based on the debate presented in the Colombian Constitutional Court Decision C-404/98. The study will show the difficulties the constitutional judge encounter when she justifies the compatibility between moral rules and the constitutional standards, as well to advance in alternatives to the solutions given by the Court. At the end, it's shown how the Court abandons legal analysis in order to validate the moral rule. The study is based on legal argumentation analysis and conceptual reflection.

Keywords: Morals, law, relation between law and morals, constitutionalism, incest, positivism, legal argumentation.

\section{Dilemas sobre a relação entre direito e moral. A propósito da Sentença c-404 de 1998, da Corte Constitucional da Colômbia}

\section{Resumo}

A relação entre direito e moral é um debate constante na teoria do direito. Usualmente se considera a questão das normas jurídicas injustas. Poucas vezes se estuda esta relação a partir de normas jurídicas que unicamente perseguem fins morais. O objetivo deste documento é o estudo de dita relação, com ocasião do debate que se deu no caso da Sentença C-404 de 1998 da Corte Constitucional da Colômbia. Busca-se mostrar as dificuldades às que se enfrenta o juiz constitucional ao justificar a compatibilidade de regras morais com a Constituição e, também, avançar alternativas ante as soluções propostas pela Corte. Se demostra que o juiz constitucional termina por incorporar a regra moral sem submetê-la a uma análise jurídica. A metodologia parte da análise da argumentação e a reflexão conceitual.

Palavras-chave: moral, direito, relação moral e direito, incesto, constitucionalismo, positivismo, argumentação jurídica. 


\title{
Dilemas sobre la relación entre derecho y moral. A propósito de la Sentencia C-404 de 1998, de la Corte Constitucional de Colombia*
}

\author{
HENRIK LÓPEZ STERUP ${ }^{1}$
}

\section{SUMARIO}

Introducción - I. ANÁLISIS ARGUMENTATIVO - A. Primer escenario: protección de la familia y la solidaridad - 1. Esquema primacía bien constitucional familia - 2. Esquema del argumento sobre solidaridad - B. Segundo escenario: debate sobre la moral - C. Tercer escenario: los alcances de la restricción - II. PRECISIÓN DEL DEBATE Y ALTERNATIVAS. - A. Precisión del debate - B. Alternativas - 1. Debate sobre la moral -2. Debate sobre el alcance de la restricción - C. Propuesta - RECAPITULACIÓN Y CONCLUSIONES - Referencias.

* Cómo citar este artículo: López Sterup, H. (Junio, 2016). Dilemas sobre la relación entre derecho y moral. A propósito de la Sentencia C-404 de 1998, de la Corte Constitucional de Colombia. Revista de Derecho Público, (36). Universidad de los Andes (Colombia). http://dx.doi.org/10.15425/redepub.36.2016.03

1. Profesor de la Universidad de los Andes. Abogado y magíster en Ciencia Política de la misma Universidad. Máster en Argumentación Jurídica, Universidad de Alicante. Doctor en Derecho, Universidad de Alicante. Correo electrónico hlopez@uniandes. edu.co 
Introducción

Los debates en torno a las relaciones entre moral y derecho han sido una de las constantes de la evolución de la teoría del derecho. En el campo de la aplicación, estos debates adquieren contornos singulares, que concretan la discusión en puntos específicos y usualmente complejos para la sociedad. En el caso colombiano, esta no ha sido la excepción. Desde temprano, en la actividad de la Corte Constitucional se ha acudido a diversos argumentos extrajurídicos, sean morales, religiosos o de otra índole, para solucionar problemas constitucionales diversos. Tal fue el caso de la Sentencia C-013 de 1997, en la que la Corte acudió a la encíclica Humanae Vitae, dictada por el papa Pablo Vı para justificar la constitucionalidad del delito de aborto. ${ }^{2}$ Con la posterior despenalización parcial (Sentencia C-355 de 2006), el debate fue reabierto, pues algunos sectores han presentado razones mo- rales (algunas religiosas) para justificar o exigir restricciones a los derechos fundamentales o para imponer barreras para el goce de derechos reconocidos. En el Congreso de Colombia se ha pretendido introducir penas más fuertes frente a ciertos delitos (violación a menores, violación a mujeres, trata de seres), con base en argumentos morales e, inclusive, el argumento moral ha fundamentado propuestas de reforma constitucional dirigidas a prohibir el aborto. En este panorama, resulta particularmente atractivo estudiar una de las pocas ${ }^{3}$ oportunidades en que la Corte Constitucional analizó, de manera directa, la relación entre derecho y moral, bajo el modelo constitucional colombiano. Asunto que, por demás, se inserta dentro de un debate teórico más amplio en torno a estas cuestiones.

El debate sobre la relación entre derecho y moral puede situarse en distintos niveles. Por una parte, si la moral puede ser condición de

2. En la sentencia se lee:

6) La mujer - considera esta Corte- no es dueña del fruto vivo de la concepción, que es, en sí mismo, un ser diferente, titular de una vida humana en formación, pero autónoma. Por lo tanto, no le es lícito disponer de él.

Afirma el Papa Pablo VI en su Encíclica “Humanae Vitae”:

“[...] si no se quiere exponer al arbitrio de los hombres la misión de engendrar la vida, se deben reconocer necesariamente unos límites infranqueables a la posibilidad de dominio del hombre sobre su propio cuerpo y sus funciones; límites que, a ningún hombre privado o revestido de autoridad, es lícito quebrantar. Y tales límites no pueden ser determinados sino por el respeto debido a la integridad del organismo humano y de sus funciones [...]"

Por ello, el amparo constitucional a la vida de las personas no se agota en la adopción de decisiones o en la consagración de medidas legislativas, administrativas o policivas que impidan o castiguen las agresiones mortales de parte de sus congéneres, o que prevengan, con miras a la conservación de la especie, las consecuencias desencadenadas por guerras, ruinas o catástrofes, sino que se proyecta necesariamente a la época que precede al nacimiento de la persona. A nadie escapa que la muerte prematura del ser humano en gestación elimina de raíz y de manera violenta las posibilidades de su futura existencia, ante lo cual el Estado no puede permanecer indiferente.

Es evidente que la Corte Constitucional soporta la ausencia de licitud para disponer de la vida humana en formación en la encíclica Humanæ Vitae, y ella misma es base para concluir sobre el alcance de la protección constitucional a la vida.

3. Aunque previamente había estudiado el texto "la costumbre, siendo general y conforme con la moral cristiana, constituye derecho, a falta de legislación positiva”, del artículo 13 del Código Civil colombiano, la decisión no tuvo el alcance que aquí se considera. También existe una copiosa jurisprudencia sobre la noción de "moral social" que, igualmente, no enfrenta, con la misma intensidad el problema teórico aquí abordado. 
validez del derecho. Por otra, por ejemplo, si dentro del derecho caben argumentos o razones morales.

La primera aproximación a la relación en cuestión corresponde al debate generado con ocasión de las posturas iusnaturalista y positivista. Si bien pocos abrazarían la tesis iusnaturalista extrema -todo derecho inmoral es inválido-, la tesis extrema de exclusión -la moral nunca es criterio de validez para el derecho- sigue siendo defendida por diversos autores de corte positivista (Ferrajoli, 2011). ${ }^{4}$ Entre quienes proponen la existencia de una relación -sea contingente o necesaria- entre derecho y moral, se encuentran aquellos que plantean el caso de la extrema injusticia como fuente de invalidez (Alexy, 2001b) ${ }^{5}$ o los que pretenden el llamado "positivismo incluyente".

El segundo punto es más complejo de caracterizar. No obstante existir consenso en que el derecho positiviza valores morales y que muchos de tales valores están incorporados al sistema jurídico, surge la discusión de si ellos se tornan autónomos respecto de la moral, es decir, si se convierten en valores jurídicos, con el derecho como único referente, o si mantienen alguna relación -directa o próxima- con la moral, de suerte que tienen una autonomía total o parcial frente al sistema jurídico. Un autor como Luigi Ferrajoli se adscribiría a la pri- mera tesis, mientras que Carlos Santiago Nino advertiría sobre la imposibilidad de la postura ferrajoliana.

Ahora bien, cuando el legislador adopta un vaIor moral y, por ejemplo, eleva a conducta ilícita una acción moralmente reprochable, surge la cuestión de si la razón moral es suficiente para validar la norma que adopta el legislador o si el juez puede legítimamente invocar dicha regla moral para juzgar (validar) la regla jurídica construida a partir de ella. Prima facie la respuesta es negativa, pues en uno y otro caso el legislador y el juez están sujetos a parámetros constitucionales.

No obstante, de admitirse de manera absoluta esta idea, inexorablemente se llegaría a la tesis de que el valor moral incorporado al derecho se torna autónomo frente al sistema moral, pues tanto su inclusión como su "funcionamiento" dentro del sistema jurídico estarían sujetos a estándares propios del derecho.

Pues bien, si se asume una relación necesaria o contingente entre moral y derecho ha de partirse de que la consecuencia anotada no es admisible, por contradecir el presupuesto del cual se parte, por cuanto termina por negar dicha relación. Es necesario, a fin de que dicha relación sea efectiva, que la moral mantenga un margen de autonomía respecto del

4. Su obra magna, Principia luris, está estructurada en torno a esta idea. Apoyándose en el principio Auctoritas, non veritas facit legem, critica abiertamente la idea de la conexión necesaria entre derecho y moral y, en particular, la pretensión de corrección que propone Alexy (Ferrajoli, 2011, pp. 15-16).

5. Un importante estudio sobre esta relación se puede encontrar en su texto El concepto y la validez del derecho, (1997), en particular el capítulo segundo. Más explícito es el artículo “Una defensa de la fórmula de Radbruch” (Alexy, 2001b). 
derecho. Pero, a la vez, si se exige que la regla moral incorporada mantenga su "validez" al margen del derecho, se termina sustituyendo el derecho por la moral.

En pocas ocasiones los jueces asumen de manera directa estos dilemas. En lo que sigue, se analiza la Sentencia C-404 de 1998, en la que la Corte Constitucional de Colombia, con ocasión de una demanda de inconstitucionalidad contra el tipo penal incesto, estudió si los argumentos morales podían o no ser fundamento de la decisión judicial.

La sentencia es de enorme interés, principalmente por la cuestión teórica que enfrenta. Con todo, su análisis muestra que la aproximación al tema es harto compleja, al punto que la solución adoptada en esa oportunidad se revierte en una estructura argumentativa que no permite, en últimas, establecer la justificación de algunas de las consecuencias normativas - derechos sexuales de las personas adultas- derivadas del tipo penal objeto de juzgamiento constitucional.

Además, por otra parte, al hacer una definición operativa de moral y establecer los contornos bajo los cuales los argumentos morales pueden ser razones para decisiones judiciales, fija un parámetro de decisión para futuros asuntos, así como pautas para la aplicación interna de tratados internacionales, como la Convención Americana sobre Derechos Humanos -Pacto de San José-, que expresamente autoriza res- tricciones a los derechos a partir de razones morales. Definición operativa que, por otra parte, parece ser de complejo seguimiento.

Finalmente, en el plano teórico, la decisión es profundamente enigmática en cuanto a la adscripción a una determinada corriente teórica. Como se podrá advertir en el estudio, en algunos aspectos la decisión se apoya en claros elementos que Aguiló (2008) ha denominado postpositivistas, en otros el vínculo con tesis positivistas es más que evidente.

Ante este panorama, la decisión que se estudia tiene una enorme complejidad pues encarna, en sede judicial, uno de los principales debates de la ciencia jurídica, como es la relación entre derecho y moral. La Corte se debate entre la legitimidad de que el legislador adopte principios morales como razón para legislar -positivizar principios morales- y el carácter arbitrario de que el juez considere principios morales para decidir en sede constitucional. La controversia reviste un enorme interés, habida consideración de que diversos estatutos facultan a los parlamentos y congresos para imponer restricciones al ejercicio de los derechos con base en principios morales, y surgen dificultades para lograr controlar dichas restricciones.

El estudio se dirige a mostrar, a partir de la estructura argumentativa (justificatoria) de la decisión y la aclaración ${ }^{6}$ de voto, que el esfuerzo por proponer una definición de moral social,

6. Se mantendrá la denominación aclaraciones, a pesar de que, como se observará en el análisis, en realidad contienen varios elementos que fuerzan a sostener que se trata de salvamentos parciales de voto. 
dirigido a apoyar el juzgamiento de la positivización de reglas morales, aunque teóricamente parece razonable, en la práctica termina por ocultar la libre incorporación de dichas reglas morales al sistema jurídico.

Para el análisis de la estructura argumentativa de la sentencia y sus aclaraciones de voto se ha optado por seguir la propuesta esquemática de Toulmin $^{7}$ (2007), con algunas precisiones que se harán en su oportunidad, pues en los argumentos aparecen elementos no considerados en su esquema, que son de interés mostrar.

En lo que sigue, el documento se organiza en tres secciones. En la primera se analiza y evalúa la estructura argumentativa de la decisión; en la segunda se analizan los problemas teóricos de la solución adoptada y se plantea una revisión de esta y, finalmente, en la tercera se hará una síntesis y conclusiones.

\section{ANÁLISIS ARGUMENTATIVO}

En Sentencia C-404 de 1998, la Corte Constitucional declaró exequible (constitucional) el artículo 259 del Código Penal de Colombia de 1980. La disposición acusada establecía: “Artículo 259. El que realice acceso carnal u otro acto erótico sexual con descendiente o ascendiente, adoptante o adoptivo, o con un hermano o hermana, incurrirá en prisión de seis (6) meses a cuatro (4) años."

Según el demandante, la prohibición de realizar actos sexuales de cualquier índole entre miembros del grupo familiar viola el derecho fundamental al libre desarrollo de la personalidad y, en general, a la libertad, pues el incesto es “una acción privada que no ofende siquiera la moralidad pública, sino que únicamente concierne a la moral individual" y como acto privado, debe ser inmune a la acción del Estado.

7. El esquema analítico de Toulmin ofrece un modelo sencillo, aunque complejo, para analizar argumentos. Está concebido a partir de una estructura que identifica una afirmación o un hecho (dato -D-), un operador lógico (modal -M-) y una conclusión (C), que se justifica a partir de un recurso o razón (garantía -G-), el cual, a su vez, se apoya en otras razones (respaldos -R-). A lo anterior se suma la incorporación de excepciones (E), que definen condiciones bajo las cuales la conclusión es inválida. El esquema, tomado del propio autor (Toulmin, 2007, p. 141) es el siguiente:

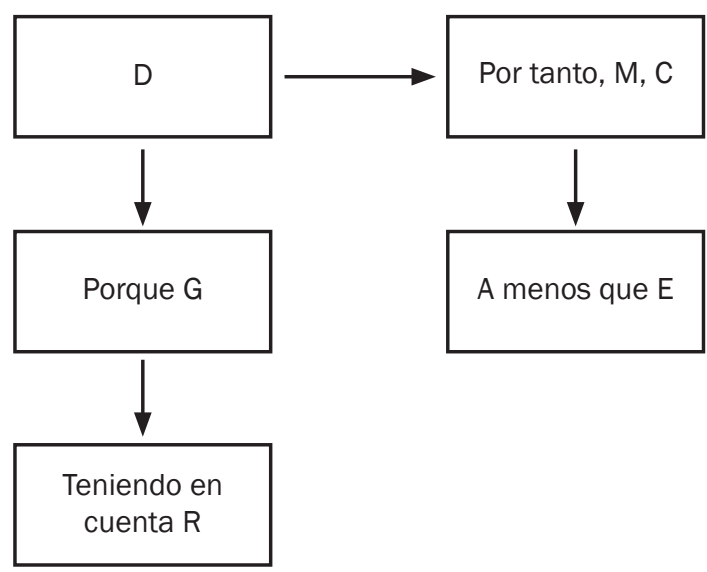


La decisión de la Corte Constitucional presenta tres escenarios argumentativos, que serán objeto de análisis en este acápite. Tales escenarios corresponden a los siguientes temas: protección de la familia y la solidaridad; moral social como base para decidir temas de constitucionalidad; y, la autonomía sexual de los adultos. Se ha optado por distinguir estos escenarios, dado que la postura de los miembros de la Corte cambia en cada uno de ellos, y la naturaleza de los argumentos y su estructura argumentativa varía en cada sección.

\section{A. Primer escenario: protección de la familia y la solidaridad}

El primer escenario que la Corte Constitucional considera es aquel en que se presenta unanimidad sobre la justificación de la constitucionalidad de la restricción (prohibición) del incesto.

En este escenario propone dos argumentos para justificar la constitucionalidad de la prohibición del incesto, ligados a la institución constitucional familia y al valor solidaridad. El planteamiento del juez constitucional está dirigido, en ambos casos, a justificar por qué es legítimo restringir el derecho fundamental al libre desarrollo de la personalidad, en aras de proteger el bien constitucional y el valor mencionados.
Los dos argumentos tienen similitudes que permiten ubicarlos en dirección a resolver una colisión entre principios (Alexy, 2001a), de manera que la tensión se daría entre el libre desarrollo de la personalidad, que obligaría a permitir el incesto, y la protección de la familia y la solidaridad, que autorizan ${ }^{8}$ prohibir el incesto. Se arriba a esta conclusión pues, como se verá, la estructura del argumento se dirige a justificar un extremo de la tensión y, a la vez, su carácter absoluto -derivado de la primacía de uno de los principios- impide cualquier espacio para considerar el principio contrario. Así, por ponerlo de alguna manera, el juez constitucional se debate entre el argumento del demandante, para quien ha de primar el libre desarrollo de la personalidad, y los argumentos de los demás intervinientes, quienes proponen la primacía de la familia y la solidaridad.

Por otra parte, aunque estructuralmente ambas argumentaciones son similares, 9 entre ellas existen enormes diferencias y desarrollos particulares, como pasa a mostrarse.

\section{Esquema primacía bien constitucional familia}

La figura 1 desarrolla el esquema de la argumentación dirigida a justificar la primacía de la institución constitucional familia:

8. Se ha optado por la expresión autorizar, pues, como se advierte en la Sentencia C-241 de 2012, la tipificación penal no es el único medio para lograr la protección del bien jurídico y el valor mencionados.

9. Ambas pueden estructurarse bajo la idea de colisión de principios y la creación de una regla, en el marco del modelo de colisión de principios de Alexy (2001a). 
Figura 1. Argumento de protección a la familia

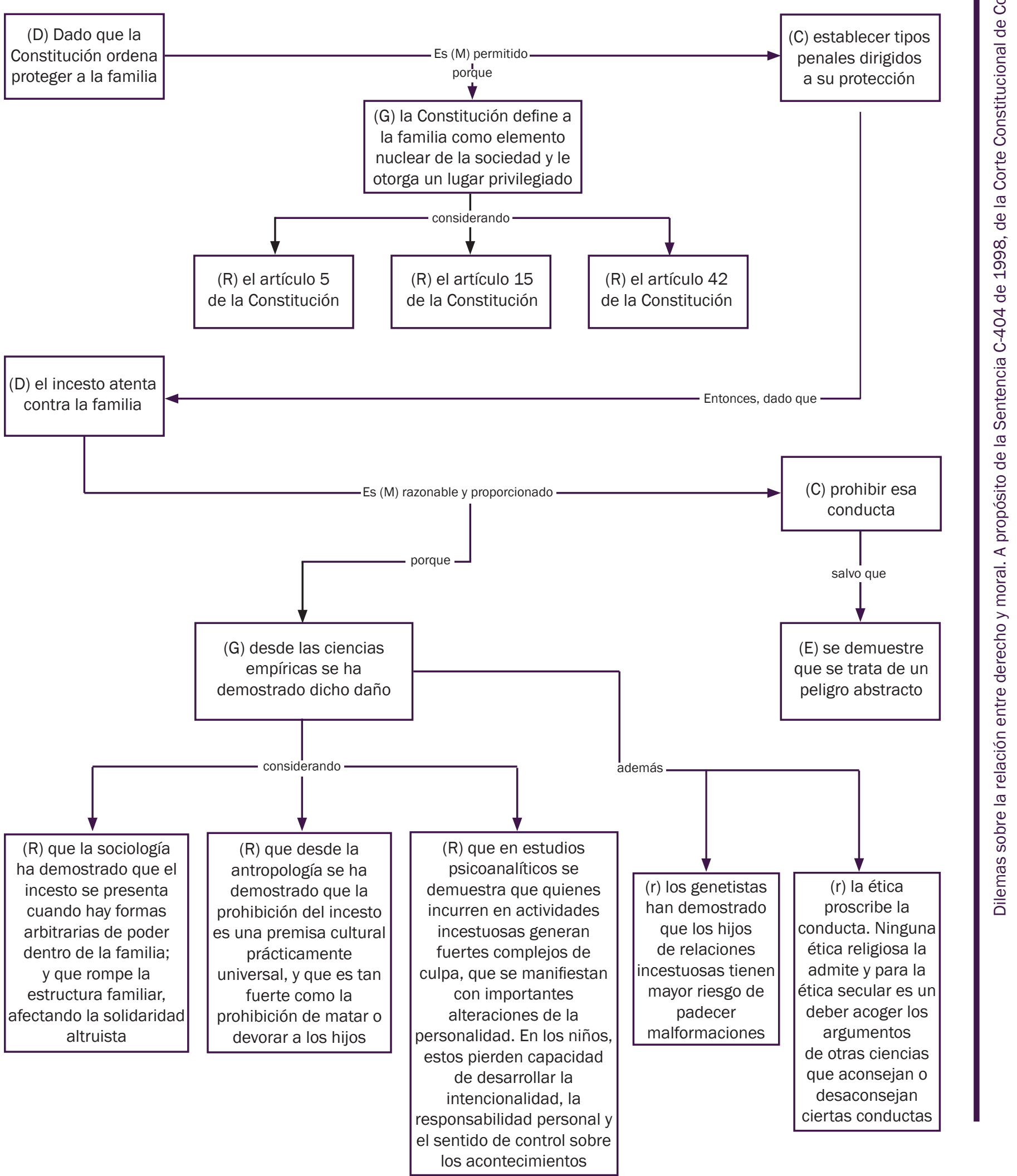


A lo anterior suma el mismo juez dos argumentos, que la propia Corte Ilama adicionales: el riesgo de malformación genética derivado de las prácticas incestuosas y el rechazo moral -tanto de la moral religiosa como secular- a esta práctica. Llama la atención que de manera expresa el juez constitucional niega a estos dos argumentos fuerza decisiva dentro de la justificación; es decir, con base en tales argumentos no es posible justificar la constitucionalidad de la prohibición. ${ }^{10}$ Frente a ello cabe preguntarse, ¿a qué se debe su inclusión dentro de la argumentación? Claramente son recursos retóricos, siguiendo una pendiente del siguiente estilo: está demostrado que el incesto es dañino por las razones $\mathrm{X}, \mathrm{Y}$ y Z, pero, además, todos sabemos que esa conducta genera malformaciones y que el incesto es éticamente reprochable. Claramente se trata de un llamado dos éndoxa, presentes en la cultura colombiana y, probablemente, en la occidental en general.

A partir de las dos direcciones de los argumentos identificados en este razonamiento es posible verificar que el juez constitucional se apoya en una racionalidad dialéctico-retórica. En efecto, al justificar la razonabilidad de la prohibición en el daño que causa el incesto en la familia, se advierte que parte de aceptar la plausibilidad de la opinión de que, si una conducta es dañina para un bien, institución o valor jurídico, está justificado prohibirla. Dicha tesis (éndoxa) está sustentada en las opiniones de los expertos (sabios) -y la evidencia empírica en que soportan sus apreciacionesy, al parecer, de la mayoría. Así, concluye que dado que existe una alta probabilidad de que ocurra el daño, es legítimo impedir la conducta que lo causa. Pero, ello no parece ser suficiente, a pesar de que se dirige principalmente a un auditorio preparado (el jurídico), de suerte que acude al horror de la malformación y al terror de la pérdida de valores. Nótese que los argumentos de horror y terror no se presentan como razón suficiente para demostrar el daño, pero claramente se ubican como un refuerzo (por acomodar la terminología de Toulmin) del argumento global. Fungen como una "garantía retórica".

\section{Esquema del argumento sobre solidaridad}

La argumentación dirigida a justificar la primacía del principio de solidaridad tiene sus propias singularidades. La figura 2 muestra el esquema de dicha argumentación.

En este punto la argumentación es más difícil de desentrañar, porque el juez constitucional acude a una estructura engañosa. Construye un principio deóntico que le permite vincular solidaridad y libre desarrollo de la personalidad, consistente en que del primero se deriva un deber -que rige la lectura del segundo-

10. Estos elementos desbordan el esquema analítico de Toulmin, pues no fungen como soporte de los respaldos o de las garantías ofrecidas. Este hecho resulta de suma importancia a la hora de considerar la inclusión de una suerte de éndoxas, con funciones retóricas. 
Figura 2. Protección del principio de solidaridad

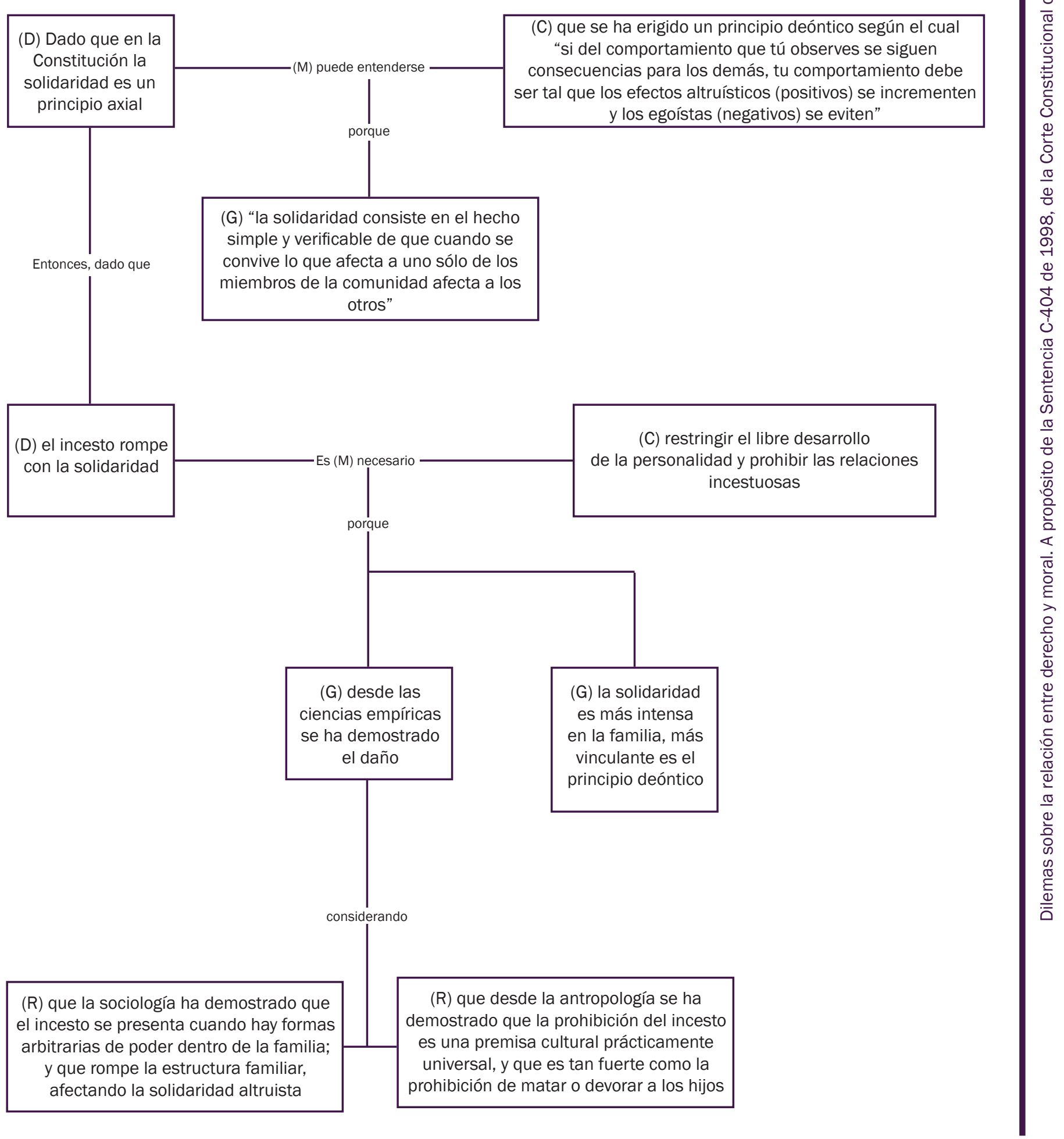


de promocionar los efectos altruísticos de los comportamientos que afecten a los demás. A la hora de aplicar este principio deóntico al caso se advierte que la argumentación se bifurca, pues de una parte insiste en probar con base en evidencia científica- el daño que el incesto causa a la solidaridad intrafamiliar y, por otra, a justificar que el principio deóntico tiene más fuerza en las relaciones familiares, debido a que dentro de ellas los vínculos de solidaridad son más intensos.

Frente a esta argumentación se puede afirmar que los elementos retóricos adquieren más fuerza. Estos se estructuran dentro del racionamiento retórico. ${ }^{11}$ En efecto, el juez acude a expresiones cargadas de un sentido moral, como son el altruismo y el egoísmo. Asigna al primero un valor positivo y al segundo uno negativo. Aunque ello se puede compartir, es claro que la fuerza expresiva del concepto altruismo supera con creces la idea de efectos positivos de una conducta determinada, lo mismo ocurre con el egoísmo. Así, dentro del razonamiento práctico se introduce un elemento persuasivo, que desvía la atención sobre su corrección hacia su aceptación, ${ }^{12}$ pues nadie ${ }^{13}$ discutiría que se deben promover las conductas altruistas y desestimular las egoístas.

Estratégicamente lo anterior es importante, pues oscurece el hecho de que de la argumentación respecto del segundo punto no se sigue la conclusión general a la que se arriba en la sentencia. En efecto, la afirmación "dado que el incesto rompe con la solidaridad" no aparece probada (justificada), en tanto que se apoya (y demuestra) no el daño directo a la solidaridad, sino a la familia. Es palpable que la Corte asume que la familia se estructura en torno a relaciones solidarias y así lo indica al sostener que "es de evidencia meridiana que si la solidaridad tiene vigencia en cualquier comunidad, en la más nuclear (donde los miembros conviven en la mayor proximidad física pensable), el fenómeno se da en ella con mayor intensidad", ${ }^{14}$ por lo que el daño a ella también implica la ruptura de la solidaridad. Pero este vínculo no prueba el daño a la solidaridad. Esta puede, en teoría, sobrevivir a la disolución de la familia.

¿Para qué, entonces, un argumento sobre la solidaridad? ¿No sería suficiente con demostrar el daño a la familia? La garantía que se ofrece

11. Dirigido al convencimiento. Aristóteles (1990) señala que "entendemos por retórica la facultad de teorizar lo que es adecuado en cada caso para convencer" (Ret. I1355b25). No significa esto, como advierte este autor, que la retórica es el arte de convencer, sino de reconocer lo convincente (Ret. I1355b15-17). Bajo estas condiciones, la idea de un razonamiento retórico alude a un razonamiento estructurado a partir de premisas (que se estiman) convincentes. En este caso, ciertos valores morales.

12. Se parte de que la corrección supone una relación entre la decisión o la premisa y un deber ser; por su parte, la aceptación tiene que ver con la admisibilidad de una tesis, premisa o decisión. En términos fácticos, ocurre que la admisibilidad guarda relación con el convencimiento. Aunque es deseable que lo admisible y lo correcto confluyan, no siempre es así. De ahí, precisamente, que la retórica aristotélica resulte interesante, pues una cosa es lo que debe ser y otra, lo que puede o no puede ser.

13. O, más bien, pocos abiertamente.

14. Salvo que se indique lo contrario, todas las citas textuales corresponden a la sentencia materia de análisis. 
da una luz sobre el punto. De manera explícita, al citar a Durkheim, la Corte invoca una concepción de la solidaridad desde las ciencias sociales y, así, asume este fenómeno como un hecho social. ${ }^{15}$ De esta manera la solidaridad aparece desligada de toda razón moral (en el sentido de fenómeno metafísico) y el principio deóntico identificado se entiende como una decisión autoritativa ${ }^{16}$ o, quizás, como consecuencia necesaria de la evolución de la sociedad, pero en ningún caso como expresión de un deber ser extrajurídico que se impone a la autoridad, en otras palabras, como expresión de la voluntad soberana del constituyente. Así las cosas, se intenta una ruptura entre derecho y moral. Hay un hecho (solidaridad), cuya protección es exigida jurídicamente (en tanto hecho social), y la prueba de la afectación a este hecho cardinal se demuestra científicamente.

Pero, de nuevo, ¿entonces para qué la referencia al egoísmo y al altruismo? Como se sugirió antes, su fuerza retórica es tal que oculta la perspectiva positivista en la que se apoya el argumento.
B. Segundo escenario: debate sobre la moral

El debate sobre la moral y derecho, que tiene lugar en esta decisión, pone a prueba algunas de las premisas del constitucionalismo contemporáneo, particularmente aquella según la cual existe una conexión entre derecho y moral. ${ }^{17}$ Debate que, como se verá, fue planteado de manera bastante confusa por los dos grupos que la sentencia en comento generó dentro de la Corte Constitucional. Para elucidar los términos de dicho debate podemos partir de tres preguntas que se hacen en el texto de la sentencia y de la aclaración de voto.

En la primera aclaración del voto, suscrita por los magistrados Antonio Barrera, Alfredo Beltrán, Alejandro Martínez y Carlos Gaviria, se hace la siguiente pregunta: “¿Para qué entonces enturbiar lo que es claro agregando algo tan abstruso como que, además, el incesto es atentatorio de la moralidad pública y esta constituye un límite al libre desarrollo de la personalidad?" Por su parte, en el cuerpo

15. Lo cual no le resta, en la teoría de Durkheim, su carácter moral. Por otra parte, no sobra recordar el estrecho vínculo que este autor establece entre solidaridad, derecho y moral. Sobre el particular, Durkheim (1999).

16. No en vano, en el texto sobre la división del trabajo social, Durkheim (1999) distingue entre solidaridad mecánica y orgánica, y vincula a cada forma una tipología jurídica: represiva para la primera y restitutiva para la segunda. Para un estudio sobre el tema, Monereo Pérez (2008).

17. Lo que, por otra parte, no es pacífico. Un interesante diálogo entre una visión que acoge esta conexión y aquella que la excluye se encuentra en el libro Dos modelos de constitucionalismo, donde los autores Ferrajoli y Ruiz Manero (2012) debaten en torno a este y otros puntos. En un pasaje, Ferrajoli señala a su contraparte en el diálogo: "Añado otra consideración, que es, a fin de cuentas, la más relevante en nuestras disciplinas: de las tesis éticas expresadas por normas de Derecho positivo, como son por ejemplo los principios establecidos en nuestras constituciones, no puede inferirse nada en el plano de (su) verdad moral. Pero sí puede inferirse inductivamente, en el plano de la verdad jurídica, lo que entendemos, en base a su interpretación, que tales principios expresan" (p. 68). [Cursivas en el original]. El argumento de Ferrajoli se dirige contra el argumento de Ruiz Manero sobre el objetivismo ético y, de paso, contra la tesis de Alexy sobre el vínculo entre derecho y moral. 
de la sentencia se hacen las siguientes reflexiones:

Resta preguntarse si, en casos como el presente -en los que existe una estrecha e indudable relación entre la norma demandada y un principio moral fuertemente compartido en la sociedad-, resulta procedente, y en qué grado, que el juez constitucional reconozca la existencia del mencionado principio. En otras palabras, si el argumento moral es también pertinente para adoptar decisiones constitucionales en uno u otro sentido.

\section{(...)}

5. Ahora bien, la cuestión central que se debate reside en determinar si el juez constitucional debe permanecer absolutamente marginado de las razones morales que explican o justifican la existencia de determinadas normas legales.

Planteado el debate en estos términos -algo oscuros-, resta analizar a qué responden efectivamente en la argumentación. Para ello se partirá de lo indicado en la sentencia.

La Corte buscó construir una definición operativa de moralidad pública, a partir de la cual pudiese confrontar la norma moral según la cual el incesto, en todas sus formas, es indebido, y así analizar su admisibilidad dentro del orden jurídico. Dada la complejidad de dicho esfuerzo, dedica buena parte de la sección a construirla y a justificarla, y llega a la siguiente definición operativa de moralidad pública:
La moralidad pública que puede ser fuente de restricciones a la libertad, es aquella que racionalmente resulta necesario mantener para armonizar proyectos individuales de vida que, pese a ser absolutamente contradictorios, resultan compatibles con una democracia constitucional y que, adicionalmente, es indispensable para conjugar la libertad individual con la responsabilidad y la solidaridad que hacen posible este modelo constitucional.

Esta construcción se apoya en tres elementos: por una parte, que el derecho es moral positivizada, afirmación que se soporta en que la ley suele reflejar principios morales que son compartidos por la mayoría representada en el parlamento. En segundo lugar, que de ello se desprende que el legislador está autorizado para dictar leyes que únicamente persigan fines morales. Por último, que tanto la Constitución como los tratados internaciones de derechos humanos autorizan la restricción de derechos con base en razones morales. La figura 3 presenta la estructura argumentativa de la construcción del concepto operativo de moralidad pública.

La construcción de la definición operativa de moralidad pública tiene un objetivo claro: lograr un parámetro que permita establecer si un fin moral que persigue una norma legal es compatible con el orden constitucional.

Ahora bien, la argumentación se dirige a justificar la posibilidad que el legislador dicte leyes que únicamente persigan fines morales. En tal 
Figura 3. Construcción de definición operativa de moralidad pública

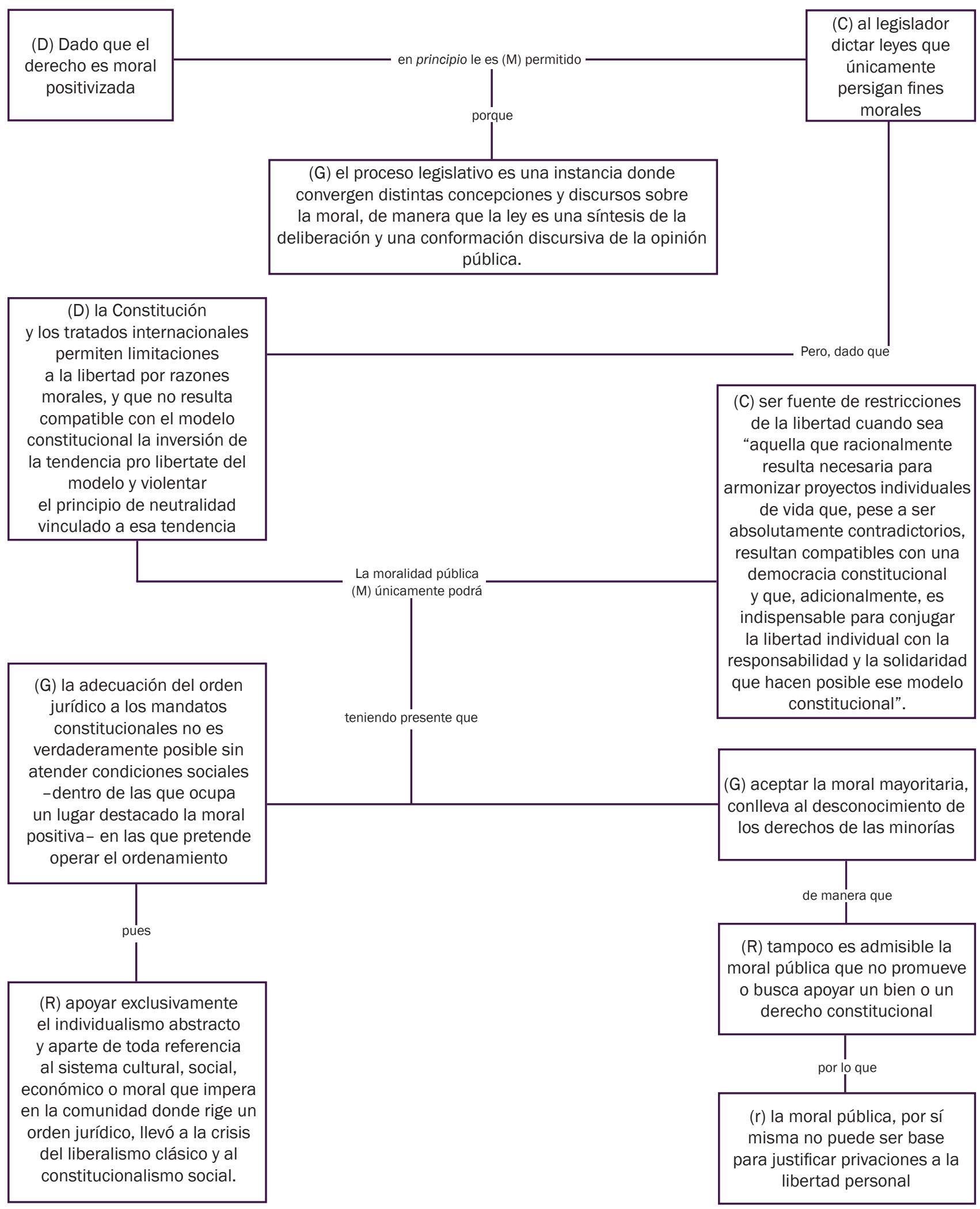


sentido, es claro que en la sentencia el juez constitucional acude a una visión habermasiana de la función del legislador, por cuanto que señala que

la ley es un medio al servicio de la razón pública que sirve desde esta perspectiva al propósito de articular normativamente consensos mínimos en una sociedad integrada por ciudadanos autónomos, libres e iguales, llamados por ello a configurar participativamente el orden político,

de lo que se desprende la legitimidad para adoptar leyes en el sentido indicado. ${ }^{18}$ Esta posibilidad está avalada por la propia Constitución y los tratados, pero, dada la necesidad de proteger el principio pro libertate, no cualquier fin moral puede ser perseguido legítimamente por el legislador.

En este marco, la definición operativa funge como tamiz para filtrar los fines morales que el legislador persiga. Ante esta función, el juez constitucional se debate entre la idea de que el derecho no puede concebirse y entenderse al margen de la realidad y el contexto moral en el cual será aplicado, por lo que rechaza cualquier asomo de individualismo abstracto y, por otra parte, que la moral mayoritaria no puede ser la base de leyes, por cuanto pondrían en riesgo los derechos de las minorías. Debido a ello, claramente cualquier restricción basada en razones morales tiene que fundarse, a su vez, en la protección de bienes o valores constitucionales.

En el plano de la estructura de la argumentación, resulta pertinente advertir que el esfuerzo argumentativo se dirige, no tanto a justificar la posibilidad de que la moral sea un fin perseguido por el legislador, como a establecer los límites a la función legislativa. En este orden de ideas, se observa que el peso de la argumentación se dirige a atenuar el riesgo de que, por considerar la moral, se subvierta el principio contramayoritario ínsito en el modelo constitucional.

Así las cosas, la definición operativa a la que arriba la Corte no admite cualquier principio moral, sino que sujeta tales principios morales a que se dirija a la realización del orden constitucional. Idea que es expresada en la sentencia de la siguiente manera:

El concepto de orden público en la sociedad democrática basada en los derechos, se refiere a las condiciones y orientaciones valorativas mínimas que deben ser respetadas por sus miembros para que esta sea una comunidad organizada en términos de libertad y para la libertad. Esta función del orden público en una democracia constitucional, forzosamente debe predicarse con

18. Debe precisarse que desde la perspectiva de Habermas, mientras se mantenga la diferencia entre el lenguaje jurídico y el moral, la incorporación de elementos morales en el derecho no significa la inmediata moralización del derecho. El espacio primario de la moral, señala Habermas, es el de la formación de la voluntad legislativa (1996, p. 206). Se agradece al evaluador anónimo advertir sobre el riesgo de que se asumiera una idea contraria, esto es, la inmediata moralización del derecho. 
la misma intensidad de cada uno de los elementos que lo integran, entre ellos, la moralidad pública. Se comprende, entonces, que la relativización de la libertad obedece a una lógica social que mira a su conservación y a su florecimiento, lo que no sería posible si los planes de vida de todos los sujetos y sus puntos de vista de orden moral, pudieran llevarse a cabo y manifestarse socialmente sin cortapisa o armonización alguna.

Planteado en estos términos, es claro que el derecho no puede desligarse de la moral, pero el argumento moral, dentro de la órbita jurídica, únicamente es válido si se ajusta a parámetros jurídicos y si se acopla a una función específica: “conjugar la libertad individual con la responsabilidad y la solidaridad que hacen posible" el modelo constitucional. En otras palabras, la razón moral termina, de alguna manera, dependiente de las razones jurídicas, perdiendo su autonomía. De ahí que se concluya que la moral no es razón suficiente para limitar las libertades constitucionales.

La aplicación práctica de esta definición operativa de moralidad pública supone para la Corte que el principio moral ha de satisfacer un test, consistente en ser compatible con los valores y principios constitucionales, respetar la dignidad humana y promover un orden justo. La figura 4 esquematiza cómo la Corte analiza la prohibición del incesto a partir de tal test.

La lectura de las razones que se ofrecen para apoyar la legitimidad de restringir la libertad personal con base en el principio moral de pro- hibición del incesto muestra elementos que no se habían considerado a la hora de construir la definición operativa. En efecto, la argumentación sustenta la necesidad (elemento racional) de la restricción por el daño a la familia y al principio de solidaridad, para luego pasar a demostrar que no se está frente a una valoración producto de la mayoría parlamentaria. Es decir, busca probar que se está frente a un principio moral que supera particularidades grupales o individuales y que no es producto de un momento histórico o de una opinión efímera. Intenta caracterizar este principio moral como fundacional de la sociedad misma, lo que explica la muy marcada referencia al tabú del incesto. Se lee en la sentencia:

16. La materia sobre la que recae la prohibición del incesto, fue tal vez la primera que reivindicó la sociedad como un todo para sí. Recuerda el profesor Guillermo Páramo Rocha, que para Lévi-Strauss la prohibición del incesto representa la "verdadera marca de la cultura, comparable al empleo de instrumentos y al lenguaje articulado", la cual sirve de "frontera (o puente) que separa (o une) lo cultural y lo natural". En el mismo estudio, el ilustre profesor, alude al sistema normativo de los muiscas, y recoge el siguiente testimonio de Fray Pedro Simón: "Si alguno se hallase que tuviese cuenta con su madre, hija, hermana o sobrina, que entre ellos eran grados prohibidos, los metiesen en un hoyo angosto de agua con muchas sabandijas venenosas dentro y cubriéndolo con una gran loza lo dejasen pereciendo allí, y la misma pena se daba a ellos" (Noticias Historiales VI, vii, 3). 
(D) Dado que el criterio moral de prohibición del incesto cumple con las condiciones para ajustarse a los principios y valores constitucionales, que respeta la dignidad humana y no es incompatible con el orden justo
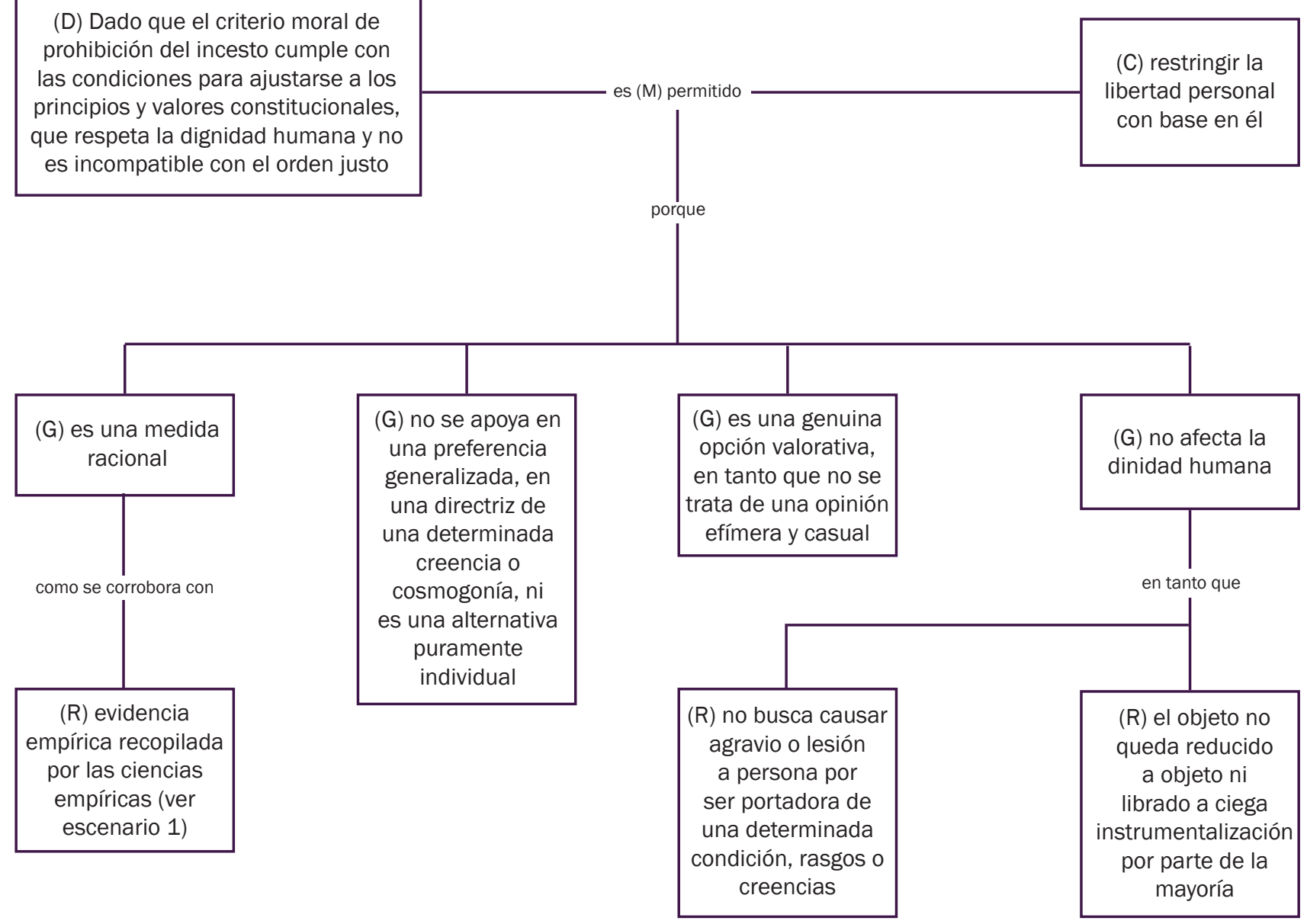

Esta última consideración no es de poca monta, como pasa a explicarse. Las garantías identificadas en la argumentación pueden agruparse de la siguiente manera. Por un lado, aquella que se califica de racional, soportada en la evidencia empírica. La referencia a dicha evidencia y a estudios de ciencias sociales enfatizan un criterio objetivo: la ciencia ha demostrado que el incesto es dañino. Por otro, se agrupan las garantías relacionadas con las condiciones de las razones morales. Estas pretenden demostrar el carácter universal y atemporal de tales razones (el tabú). Finalmente, la última garantía busca mostrar el respeto a la dignidad humana, por cuanto la razón moral analizada no es discriminatoria y, menos, denigra de la condición humana del individuo.

A partir de ello podría sostenerse que la Corte, en realidad, sustenta la validez de la res- 
tricción basada en el argumento moral en la fuerza y el peso de la propia razón moral. Por ello la referencia al tabú. En efecto, como se desprende del punto anterior, las razones justificatorias (garantías) giran en torno al valor, antes que a su relación con el derecho. Luego se volverá sobre este punto.
La primera aclaración del voto, por su parte, considera que no es posible, de manera inequívoca y racional, justificar una restricción al libre desarrollo de la personalidad, con base en invocaciones o principios de la moralidad pública. La figura 5 corresponde al esquema de esta argumentación.

Figura 5. Aclaración de voto contra referencia a moralidad pública

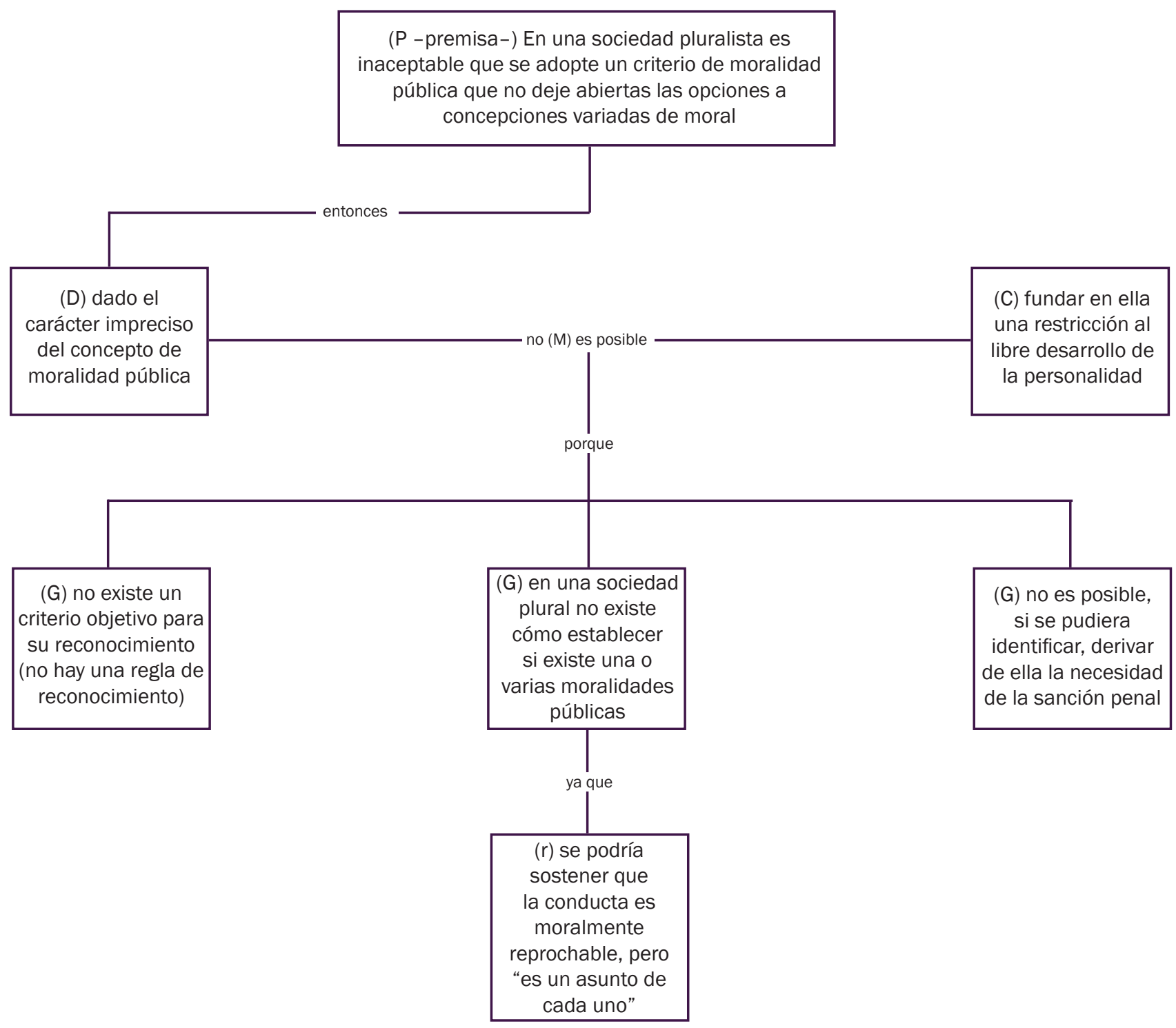


Como se puede apreciar, la argumentación se basa en la imposibilidad de establecer qué principio moral corresponde a una moral públi$\mathrm{ca}$, en las dificultades para definir su alcance y para identificar una que sea compatible con las distintas visiones existentes en una sociedad plural. La argumentación es muy sencilla, pero no por ello, como se estudiará más adelante, superflua. Desde el punto de vista de la estructura del argumento, las garantías se dirigen a apoyar el dato de que el concepto de moralidad pública es impreciso. No obstante, se advierte que una de las garantías ofrecidas, en realidad, busca mostrar que en una sociedad plural es imposible identificar una moralidad pública común a ellas, lo que significaría que cualquier apelación a la moralidad pública implica la imposición de ella sobre quienes no comparten dicho principio moral.

Un punto merece una consideración especial. Se afirma que, de identificarse una moral universal, de ella no podría derivarse la "necesidad" de la sanción penal. Quienes suscribieron la primera aclaración de voto habían apoyado la tesis expuesta en el primer escenario. Como se recordará, en dicho lugar la tesis positivista, dirigida a desligar moral y derecho, campea. En últimas, el reproche penal se soporta en el dato objetivo de la destrucción del hecho social solidaridad. La necesidad de la protección se justifica en la decisión autoritativa de proteger la solidaridad y la familia. En ningún momento porque la solidaridad sea un valor moral o porque el legislador invoque una regla moral. La necesidad del reproche descansa, en últimas, en la voluntad del soberano (Auctoritas non veritas facit legem).
Se retoma así, junto a las demás razones, la tesis excluyente que niega la conexión necesaria entre derecho y moral y, más aún, rechaza la idea de una moral universal o una justificable. La aclaración no avanza sobre las consecuencias de esta postura.

\section{Tercer escenario: los alcances de la restricción}

Tanto el demandante, como algunos intervinientes dentro del proceso, consideraron que bien podía prohibirse el incesto cuando tuviese lugar entre adultos y menores o entre menores, pero que, tratándose de adultos, la prohibición resultaba excesiva. Frente a este punto la Corte se dividió y en este aparte se consideran las dos argumentaciones.

Para la mayoría, como se aprecia en la figura 6 , el principio moral de prohibición del incesto tiene una fuerza propia que impide al juez constitucional modificar su alcance legal.

La Corte asume que cuando el legislador dicta leyes apoyadas en este tipo de principios o reglas morales, la función del juez constitucional se limita a verificar su compatibilidad o incompatibilidad con el orden constitucional, a la manera del legislador negativo de Kelsen. Al considerar la argumentación, se advierte una pobreza justificatoria significativa, que se pretende suplir con la tesis de que la prohibición del incesto tiene una función de cohesión y de definición cultural, con lo que se proyecta la fuerza del tabú sobre el funcionamiento de los órganos estatales. 


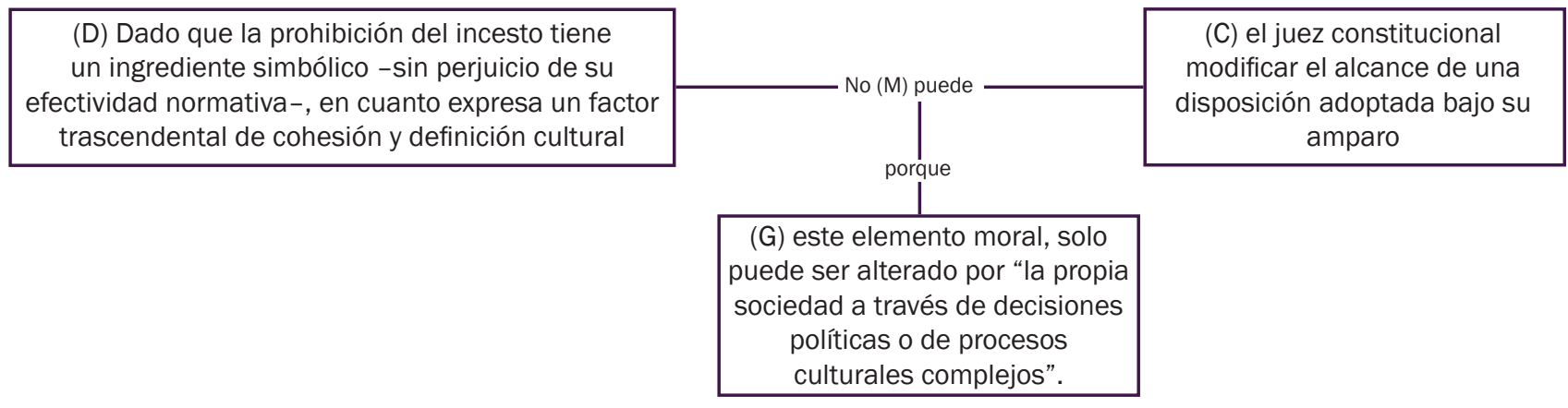

Quizás sea en este punto donde se evidencia de manera más clara el quiebre argumentativo de la Corte. En el segundo escenario, como se estudió, la Corte termina por sujetar la validez y alcance del principio moral invocado a su compatibilidad con el orden jurídico constitucional. Aquí, por su parte, se desdice y termina por aceptar, de manera acrítica, el alcance propio de la tacha moral. Es decir, de la mano de la Corte Constitucional, el orden jurídico renuncia a fijar los parámetros y límites a los principios morales; los cuales, además, parecieran quedar por fuera del alcance del legislador, pues es la propia sociedad la que debe alterarlos.
La minoría -constituida por los magistrados que suscribieron la segunda aclaración de voto: Antonio Barrera, Alejandro Martínez y Carlos Gaviria-, considera que si se trata de adultos que no conviven en el seno familiar, la prohibición del incesto debe morigerarse. Señalan que debe entenderse que en este caso no existe una real lesión del bien jurídico, de manera que no puede calificarse la conducta de antijurídica. Empero, no ofrecen razones que expliquen por qué no se presenta la lesión al bien jurídico, como se observa en la figura 7.

Figura 7. Justificación de la conducta en determinados casos

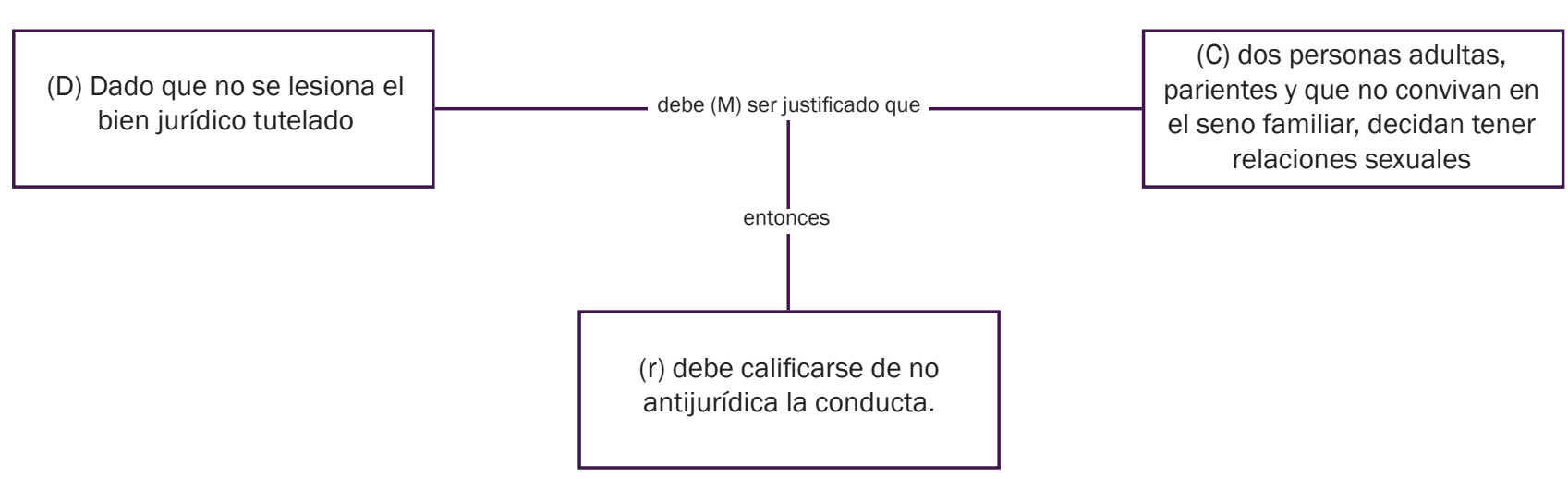


El que no ofrezcan suficientes razones para sustentar su posición merece alguna reflexión. En primer lugar, dada la caracterización sociológica de la solidaridad que acogen, han debido demostrar cómo ella no se ve afectada en el supuesto analizado. En segundo lugar, han debido hacer explícito el concepto de familia que invocan, pues no se explica cómo dicho concepto se altera por el hecho de que miembros adultos que no conviven, mantengan relaciones sexuales. Los lazos de solidaridad, salvo explicación en contrario, no se rompen por la circunstancia de no convivencia.

En la siguiente sección se volverá sobre argumentos planteados por la mayoría y quienes suscribieron la aclaración de voto, a fin de desentrañar algunos elementos adicionales.

\section{PRECISIÓN DEL DEBATE Y ALTERNATIVAS}

En la primera sección de este estudio se ha presentado y evaluado la estructura argumentativa de los tres escenarios identificados en la Sentencia C-404 de 1998 de la Corte Constitucional de Colombia. En este apartado, primeramente, se precisará el debate, para luego proponer alternativas de comprensión de la propuesta del tribunal.

\section{A. Precisión del debate}

Son los escenarios dos y tres en los que es posible ubicar la existencia de un debate y cabe confrontar los argumentos. Una de las dificultades para realizar esta tarea es identificar los extremos de los respectivos debates. Si bien, conforme a la estructura general de la sentencia, frente a la postura mayoritaria se expresan aclaraciones de voto, que más bien parecen salvamentos parciales de voto, del análisis de las argumentaciones se desprende que no es evidente ante qué aclaran el voto o si la Corte responde al punto.

En primer lugar, se cuenta el debate sobre moral. En principio, pareciera que el debate se centró en discutir si un principio moral podía ser base para restringir un derecho constitucional. No obstante, para la mayoría la cuestión es si es legítimo que el legislador persiga la realización de un fin moral. A primera vista estas discusiones son iguales, pues podría sostenerse que, en uno y otro caso, termina por debatirse la cuestión de si el legislador puede perseguir el fin moral. Sin embargo, en la tesis general la cuestión queda abierta a si razones morales pueden ser adoptadas por distintas autoridades -legislador, ejecutivo o juez-, a la hora de imponer límites a los derechos constitucionales. Ello es posible pues, aunque las restricciones a los derechos fundamentales deben adoptarse por vía legislativa, no puede perderse de vista que ciertas decisiones administrativas pueden incorporar, puntualmente, razones morales (como ocurriría en ejercicio de ciertas facultades discrecionales) y tales razones pueden ser base de soluciones judiciales. De ahí que sea posible distinguir, para efectos de comprender el argumento analizado, entre las dos hipótesis. 
Por su parte, para quienes suscriben la primera aclaración del voto, el problema es si la moralidad pública puede ser un argumento que defina la constitucionalidad de una medida restrictiva de un derecho. Así, la problemática en un extremo -el mayoritario-gira en torno al control de la actividad legislativa, mientras que el segundo se refiere al control de la actividad judicial. En términos teóricos, el debate se da entre la legitimidad de positivizar la moral y la legitimidad del derecho porque es conforme a la moral. En la siguiente subsección se volverá sobre este debate.

El siguiente escenario de controversia gira alrededor de la extensión de la prohibición. Para la mayoría, el debate es si corresponde o no al juez constitucional introducir limitaciones al alcance de un principio moral como el analizado (prohibición de incesto), mientras que para la minoría es si resulta legítimo mantener una prohibición basada en razones morales, cuando el bien jurídico tutelado no se lesiona. Así, los extremos del debate se dan entre la competencia del juez constitucional y el juicio de proporcionalidad de las medidas restrictivas de los derechos.

\section{B. Alternativas}

Según se ha mostrado en el apartado anterior, el debate al interior de la Corte estaba lejos de ser claro, en particular porque hay una ruptura dentro del diálogo, en la medida en que las tesis de un lado y del otro no parecen apuntar a la misma dirección. Así, ante dicha ruptura, es necesario identificar un punto en común, que permita reconducir el debate.

1. El debate sobre la moral

La tesis minoritaria en este escenario, que se ha reconstruido en torno a la pregunta de si el derecho es legítimo porque es conforme a la moral, se plantea a la manera de preguntas que dirigen al auditorio a asumir la imposibilidad de un criterio objetivo de moralidad pública y, en últimas, el carácter arbitrario de cualquier pretensión de justificar el derecho a partir de la moral. Las preguntas realizadas se corresponden con aquellas que Comanducci (2003) ha hecho frente a lo que él denomina el neoconstitucionalismo ideológico y el neoconstitucionalismo metodológico. En relación con ellos ha advertido que, en uno y otro caso, se está frente a la imposibilidad de identificar una moral positiva compartida por los jueces o por la sociedad, de suerte que la decisión judicial termina por apoyarse en "una moral subjetivamente escogida" por el juez o bien en una "moral intersubjetivamente aceptada", igualmente identificada por el juez (Comanducci, 2003, p. 94). El primer caso es inadmisible, por el elemento arbitrario que entraña y la seria amenaza a la certeza del derecho. El segundo, termina siendo imposible, pues "Ios jueces, de hecho, generalmente no poseen los instrumentos necesarios para precisar cuáles son las normas de la moral de un país" y, además, en una sociedad plural lo más probable es que "no exista homogeneidad moral en la sociedad” (Comanducci, 2003, pp. 96-97), lo 
que termina por llevar cualquier pretensión de sustentar en la moral una decisión judicial al caso de la moral subjetivamente escogida por el juez.

Esta conclusión es útil para reconducir el debate sobre la moral que se dio en la sentencia que se analiza. La tesis mayoritaria optó por analizar si la persecución de la realización de un fin moral podía ser un fin constitucionalmente válido (de ahí que se propusiera que su debate era sobre la legitimidad de positivizar un principio moral), lo que corresponde al primer paso de un juicio de proporcionalidad estándar. ${ }^{19}$ Teniendo ello presente, el debate podría dirigirse hacia la discusión de si, en abstracto, la definición operativa de moral pública que construyó la Corte Constitucional permite superar la objeción de la definición subjetiva que acusa Comanducci y si, en el caso concreto, efectivamente se presentaron argumentos suficientes para demostrar su superación.

Al revisar la argumentación de la Corte Constitucional en el segundo escenario, y la definición de moralidad pública que construyó, se advierte que parte de asumir que existe una evidente conexión entre derecho y moral, en el sentido que el derecho se produce dentro de un determinado contexto social, en el cual conviven distintas moralidades, de manera que, siguiendo a Hart, no puede discutirse seriamente que el desarrollo del derecho, en todo tiempo y lugar, ha estado profundamente influido tanto por la moral convencional y los ideales de grupos sociales particulares, como por formas de crítica moral esclarecida, formulada por individuos cuyo horizonte moral ha trascendido las pautas corrientemente aceptadas. (1992, p. 229).

Este punto es central, pues le permite a la Corte tomar distancia de quienes asumen que el derecho es un fenómeno aislado y al margen de las turbulencias morales de una sociedad; distancia que, a la vez, fuerza a aceptar que el tema moral no puede pasar desapercibido para el juez constitucional, habida consideración que "las comunicaciones políticas que se efectúan a través del filtro de la deliberación dependen de recursos del mundo de la vida"20 (Habermas, 2005, p. 378). Así, ante la inevitabilidad de la presencia de (o referencia a) la moral dentro del proceso de producción normativa, la cuestión no es dilucidar esta conexión, sino la de contenerla: definir los límites dentro de los cuales el argumento moral se torna admisible. De ahí que, cuando la Corte construye su definición operativa, no fija contenidos específicos o criterios de reconocimiento, sino de juzgamiento: ${ }^{21}$ si se cumple con determinadas condiciones, el argumento moral es admisible. En otras palabras, propone un test.

19. Sobre el particular se puede consultar a Alexy (2001), así como la copiosa jurisprudencia constitucional en la materia.

20. Ver nota $n .^{\circ} 18$.

21. Esta distinción entre criterios de reconocimiento y de juzgamiento, que claramente alude a la existencia de una regla de reconocimiento (Hart, 1992), merece alguna consideración. Conforme a Hart (1992), la regla de reconocimiento es aquella que 
Con ello, el problema de la imposibilidad de identificar una moral pública común o intersubjetivamente aceptada desaparece en sus dimensiones ontológicas y epistemológicas, pues no interesa establecer su existencia y contar con los medios para su conocimiento. En su lugar, el debate sobre la moralidad pública se dirige hacia el establecimiento de sus condiciones de compatibilidad con el orden constitucional. Por decirlo de alguna manera, se pasa de un modelo inquisitivo - descubre la verdad-a uno adversarial -propón una verdad-, de manera que el elemento argumentativo y justificatorio adquiere una marcada relevancia. Además, minimiza el riesgo de imposición de la perspectiva moral del juez, pues privilegia la opción adoptada democráticamente, por cuanto se juzga a partir de una decisión legislativa previa.

El acento de la argumentación no será, entonces, demostrar que el principio moral satisface criterios de universalidad y de aceptación general, sino si es requerido para realizar los valores y principios constitucionales. Al examinar la definición operativa es posible identificar los elementos que apuntan en esta dirección: primero se admite la posibilidad de que la moralidad pública sea fuente de restricciones a la libertad, luego se demanda que cumpla una función específica (armonizar proyectos individuales de vida compatibles con la democracia constitucional) y que opere de determinada manera (conjuga libertad con responsabilidad y solidaridad).

Ahora bien, al lograr de esta manera la superación del dilema sobre la "moralidad subjetivamente escogida", también se está fijando en otros términos el debate sobre la relación entre derecho y moral. En lugar de fincar la legitimidad de la opción por el principio moral por su propia condición moral, colocando a la moral por encima del derecho, demanda que dicha opción sea compatible con el orden constitucional. Lo que significa que la justificación del derecho es, exclusivamente, a partir del propio derecho: producir derecho conforme a derecho. De esta manera, la moral, una vez ingresa al ámbito jurídico, pierde su autonomía y su validez dependerá exclusivamente de criterios jurídicos. Cosa distinta es que la producción de derecho conforme a derecho demande la satisfacción de un conjunto de valores, contenidos

“especificará alguna característica o características cuya posesión por una regla sugerida es considerada como indicación
afirmativa indiscutible de que se trata de una regla del grupo" (p. 117). Este autor precisa que la regla de reconocimiento
puede adquirir formas complejas, y por ello podría preguntarse si el criterio de juzgamiento que se propone aquí no es una
forma de regla de reconocimiento. Para resolver el punto ha de tenerse presente que la regla de reconocimiento es “una regla
para la identificación incontrovertible de las reglas primarias de obligación” (p. 118). Ello nos lleva directamente al tema de
la validez, lo cual, traducido a un moderno constitucionalismo, podría incorporar elementos de validez material. Visto desde
esta perspectiva, es posible asimilar los criterios de juzgamiento integrantes de la regla de reconocimiento.

Sin embargo, esta aproximación impide centrar la atención en que los criterios de juzgamiento que se han mencionado apuntan a la función judicial de evaluar si una regla puede o no ser parte de un sistema jurídico. La regla de reconocimiento sugiere la existencia de una lista de verificación de condiciones, mientras que los criterios de juzgamiento demandan una actividad argumentativa y justificatoria. Sin lugar a dudas la regla de reconocimiento requiere de un estudio que desborda los alcances de este escrito. 
en el orden axiológico adoptado en la propia Constitución.

Pero esta circunstancia -existencia de un orden axiológico en la propia Constitución-, vuelve a colocar sobre la mesa el asunto que se suponía superado. ¿Es posible una aproximación a tal orden axiológico desligado de las razones morales? Joseph Aguiló (2008) plantea que el modelo postpositivista asume "el modelo de la continuidad práctica de las diferentes operaciones normativas" (p. 21). De acuerdo con esta tesis, dentro del razonamiento jurídico hay campo para el argumento político y el moral, por el compromiso con los fines y valores constitucionales. Señala Aguiló que el "razonamiento jurídico se politiza", en el sentido de que no es posible una separación tajante entre el razonamiento jurídico y el político y el moral. Por lo que difícilmente podría responder afirmativamente a la pregunta planteada. Carlos Santiago Nino había advertido esta situación, cuando trató sobre la conexión justificatoria entre derecho y moral, y precisó que "el discurso moral de la modernidad tiene un carácter imperialista que impide la subsistencia de discursos justificatorios insulares" (2014, p. 82), queriendo demostrar con ello que en la base del discurso jurídico se encuentra uno de carácter moral.

Pero esta solución no está exenta de dificultades. La idea de un continuum entre moral y derecho $^{22}$ no se presenta a cualquier nivel, so pena de anular la autonomía del derecho. Ello significa que por debajo de dicho nivel (que Nino ubica tanto en el plano justificatorio como en el interpretativo) el elemento moral debe ceder al parámetro jurídico. Pero también significa lo contrario. El imperialismo moral que señala Nino obliga a plantearse que, en el nivel superior, donde con mayor intensidad se verifica dicho continuum, es posible la disolución del derecho en la moral (o en la ética). ¿Cómo, entonces, juzgar la compatibilidad del principio moral con el derecho?

Una opción es la renuncia al juicio y asumir que la voluntad parlamentaria es suficiente, como lo propondría un positivismo formalista. Pero esta opción desconoce, precisamente, los fundamentos del constitucionalismo contemporáneo.

Pasando al caso concreto, esto es, la identificación del principio moral de prohibición al incesto como moral pública, la Corte, de manera extraña, en lugar de demostrar que satisface las condiciones que ella misma ha fijado (cumplir una determinada función y operar de cierta manera), se ocupa de reiterar que el incesto causa un daño a la familia y al vínculo de solidaridad, y a establecer que existen elementos objetivos que permiten identificarla como una moral intersubjetivamente asumida. No existe un solo argumento dirigido a establecer que la prohibición del incesto es "necesario mantener[la] para armonizar proyectos indivi-

22. Que también plantea Dworkin (2011). 
duales de vida... compatibles con una democracia constitucional". La única referencia a un elemento racional es el hecho de que, conforme a ciencias sociales y a ciencias empíricas, el incesto causa daño a las relaciones familiares, altera su estructura, rompe con la solidaridad intrafamiliar y usualmente es escenario de relaciones arbitrarias de poder. Pero de ahí a demostrar que la prohibición es necesaria para armonizar proyectos individuales de vida, hay un largo paso. El acápite dedicado a demostrar este elemento racional concluye en los siguientes términos:

12. Es perfectamente racional que el grupo social apele a una estrategia normativa -por tanto, valorativa-, para encauzar la acción social en una dirección que le permita impedir efectos perjudiciales en los distintos órdenes de la vida social e individual. La sanción, social o jurídica, cumple la misión de señalizar, de manera no contingente, comportamientos dañinos y, en cierta medida, suple la necesidad de que el sujeto deba en cada caso entrar a determinar cognoscitivamente por sí mismo el universo de efectos que se siguen de su conducta, lo cual, aunque deseable no siempre es posible en la práctica social.

De hecho, las bases científicas del tabú del incesto impuesto desde los albores de la civilización, pueden retrospectivamente sustentarse en alguna extensión con los actuales conocimientos y técnicas adquiridos en los distintos campos del saber humano, corroboración esta que, en todo caso, no le resta mérito, validez ni legitimidad a la función normativa inicialmente canalizada por el tabú, reflejada posteriormente en costumbres, usos y creencias que concluyen con la penalización positiva. Esta última, lejos de ocultar el origen mítico de la prohibición, se apropia de ella racionalmente y secunda, en el plano secular, su sentido y propósito, contribuyendo también a aliviar al individuo y a reducir-gracias a la claridad que provee sobre las posibilidades de contacto sexual genéricamente permitidas y prohibidas - la complejidad de su entorno social y las interacciones que en él pueden realizarse.

No hay duda de que efectivamente la prohibición del incesto armoniza proyectos de vida individuales, al definir las posibilidades de contacto sexual entre personas, de manera que el individuo no tiene necesidad de decidir si determinados encuentros son o no permitidos. La armonización se da por vía de reducción de tales posibilidades, de manera que los proyectos de vida parten de la delimitación de roles -esposo, esposa, madre, padre, hijo, hija-, sin el riesgo de que se trunquen o se vean amenazados por conductas que afectan lo que implica, en términos sexuales, asumir un determinado rol. No obstante, no se ofrece elemento alguno referido a su necesidad, salvo el peso del tabú mismo.

Por otra parte, no existe en la sentencia referencia alguna a la manera en que opera la prohibición. No se demuestra que permita "conjugar la libertad individual con la responsabilidad y la solidaridad". En este punto, la referencia a la dignidad humana y a su realización (por vía 
negativa: no es discriminatoria, ni instrumentaliza a la persona), únicamente prueba su compatibilidad con un determinado valor (determinante, por cierto) del orden constitucional, pero su carácter indispensable no aparece en la argumentación.

Con ello, la Corte da la razón al grupo minoritario en el sentido que no resulta posible establecer que del principio moral en cuestión se derive directamente la necesidad de su sanción penal. Ha sido constante de la jurisprudencia de la Corte Constitucional colombiana que, frente a los tipos penales, el legislador cuente con un amplio margen de apreciación, pero su justificación se apoya en la idea de que el derecho penal debe ser la última ratio y, por lo mismo, su adopción debe ser necesaria para la realización del fin constitucional de protección de un bien jurídico determinado. En el caso del incesto, existió unanimidad en que por los daños - demostrados con base en evidencia empírica- que causa se justificaba su tipificación como conducta prohibida, pero no se aportó elemento justificatorio relativo a su necesidad moral.

Aquí la propuesta sobre el concepto de moralidad pública admisible se enfrenta a uno de sus mayores retos: ¿Cómo pasar del análisis factual al valorativo? ¿Cómo mantener la argumentación de justificación de la premisa moral dentro de los cauces valorativos? Esto, por cuanto si la argumentación se apoya en lo fáctico, daño en este caso, la respuesta será, no su carga moral, sino el deber de evitar el daño y estará probada la no necesidad del argumen- to moral para el debate. Para dar respuesta a este punto es pertinente analizar el segundo debate.

\section{Debate sobre el alcance de la restricción}

En el último escenario considerado se debate el alcance de la restricción. Tal como se expuso, la mayoría optó por un argumento en torno a la competencia del juez constitucional frente a un principio moral que, como la prohibición del incesto, y en palabras de la Corte, "tiene un ingrediente simbólico... en cuanto que expresa un factor trascendental de cohesión y definición cultural". La Corte abdica a considerar un análisis sobre los límites de dicha prohibición. La minoría, por su parte, demanda dicho análisis, reclamando que se considere justificada la conducta tratándose de adultos, con pleno consentimiento y que no convivan en el seno familiar. Reclamo que no es más que una petición de que se realice un juicio de proporcionalidad de la medida restrictiva del derecho a la libertad.

Siguiendo el esquema propuesto, esta discusión se reconduce hacia un debate sobre si toda medida restrictiva de un derecho debe someterse a un juicio de proporcionalidad. La propia mayoría señala que la sanción penal está sujeta al principio de proporcionalidad estricta:

En todo caso, la sanción penal consistente en una limitación a la libertad personal no puede fundarse exclusivamente en la defensa 
de principios de moralidad pública que, a su turno, no amparen derechos o bienes constitucionalmente protegidos. ${ }^{23}$ Ciertamente, una tal restricción resultaría desproporcionada en la medida en que no podría superar el juicio llamado de estricta proporcionalidad. ${ }^{24}$

En estas condiciones, resulta sorprendente que la Corte desista del juicio de proporcionalidad y considere que la prohibición "sólo puede ser alterad[a] por la propia sociedad a través de decisiones políticas o de procesos culturales complejos que no pueden ser definitivamente impuestos por esta Corporación de manera unilateral”. ¿Qué justifica un argumento en esta línea? ¿Por qué frente a otros temas la Corte claramente altera estos procesos culturales y se impone sobre las decisiones políticas?

Una posible respuesta se encuentra dentro de la propia sentencia, cuando concluye en los siguientes términos:
Finalmente, cabe resaltar que en esta última el individuo se forma y actúa como sujeto autónomo dotado de capacidades morales para ejercitar sus derechos y cumplir los deberes de la civilidad propios de una comunidad altamente diversificada, pero no por ello privada de consensos reflexivos básicos sobre su común unidad - adoptados desde luego dentro del marco constitucional que postula el respeto a los derechos y libertades fundamentales-, indispensables para articular en una sociedad de libres e iguales, relaciones de mutuo reconocimiento, respeto y reciprocidad.

Los consensos reflexivos a que alude la Corte se logran en el escenario político, en el proceso legislativo, espacio -en términos de la Cortede “conformación discursiva de la opinión pública", lo que nos ubica en el ámbito de lo que Habermas (2005) denomina política deliberativa, y explicaría su resistencia a un juicio de proporcionalidad, al asumir, además, la crítica

23. A este respecto pueden consultarse, entre otras, las sentencias C-239/97 (M. P.: Carlos Gaviria Díaz) y C-659/97 (M. P.: José Gregorio Hernández Galindo). Sobre una cuestión semejante, el Tribunal Europeo de Derechos Humanos, en la sentencia dictada dentro del asunto Dudgeon, el 22 de octubre de 1981, manifestó: "Como ha puesto de manifiesto el caso Sunday Times, el margen de apreciación no tiene amplitud idéntica para cada una de las finalidades que autorizan a limitar a un derecho, siendo especialmente amplia cuando se trata de proteger la moral. Pero en cualquier caso hay que entender que el margen de apreciación depende no solo de la finalidad de la restricción sino de la naturaleza de las actividades en juego. En el presente supuesto que tiene por objeto uno de los aspectos más íntimos de la vida privada, deben existir razones particularmente graves para convertir en legítimas las injerencias de los poderes públicos a los efectos del artículo 8-2 [restricción de la intimidad por razones de moralidad pública]. Las motivaciones alegadas por el Gobierno irlandés, sobre el clima moral irlandés contrario a la reforma de dicha legislación y la situación constitucional por la que atraviesa Irlanda, no justifican hablar de 'necesidad social imperiosa'. Los motivos del Gobierno, que se entienden pertinentes, no son suficientes para justificar el mantenimiento de normas en la medida en que tengan por resultado general la prohibición penal de relaciones homosexuales entre hombres adultos capaces de consentirlas. En particular, de la población de Irlanda del Norte, ni las actitudes sobre la homosexualidad masculina en Irlanda del Norte, ni la creencia de que una atenuación de dichas penas no conduce a minar los valores morales existentes, no permite en sí mismo una injerencia en la vida privada del recurrente. Despenalizar no significa aprobar, y el temor de que en ciertos ambientes obtengan a este respecto conclusiones erróneas de una reforma de la legislación, no constituye una buena razón para conservarla incluso en sus aspectos injustificables".

24. Véanse, entre otras, las sentencias C-459/95 (M. P.: Eduardo Cifuentes Muñoz); C-309/97 (M. P.: Alejandro Martínez Caballero); T-067/98 (M. P.: Eduardo Cifuentes Muñoz) y T-124/98 (M. P.: Alejandro Martínez Caballero). 
de Habermas a la jurisprudencia de valores o la adopción de un orden de valores y a la realización de juicios de ponderación:

El Tribunal Constitucional se transforma así en una instancia autoritaria... al dejarse guiar por la idea de realización de unos valores materiales que vendrían previamente dados en términos de derecho constitucional. Pues si en caso de colisión todas las razones pueden cobrar el carácter de argumentos concernientes a fines, desaparecen esos cortafuegos que con la comprensión deontológica de las normas y principios jurídicos quedan introducidos en el discurso jurídico. (Habermas, 2005, p. 332).

Así pues, la Corte abraza la política deliberativa y el principio de legitimidad derivado del proyecto habermasiano. Con todo, de manera paradójica ${ }^{25}$ renuncia al modelo de la conexión interna entre derechos y principios constitucionales y el orden jurídico (Aguiló, 2008), pues la legitimidad del orden jurídico no partirá de la "concreción de los derechos a partir de una "razonable" ponderación de bienes y principios constitucionales" (Aguiló, 2008, pp. 68-69), sino de su producción conforme al consenso reflexivo y la pretensión (quizás, la esperanza) de que la actividad legislativa no desborde el marco constitucional (en la idea de conexión externa de que habla Aguiló). En el caso concreto, pareciera que la Corte asume que el consenso reflexivo generado en la sociedad y recogido por el legislador le permite optar, de manera discrecional (y sin límites), por un principio moral que ella misma define como fundamental para la sociedad.

La argumentación de la Corte, entonces, se dirige a demostrar que la única moralidad pública admisible es aquella que satisface su definición operativa, pero una vez satisfecha esa condición queda libre del juicio jurídico de ponderación, tornándolo en absoluto e inasible para el derecho. No es extraño, entonces, que hubiese recurrido al horror de la malformación genética y al terror de perder los valores morales, para apoyar su argumentación. Habría rematado magistralmente recordando la "decadencia moral” de César y Lucrecia Borgia y al imaginario sobre las malformaciones genéticas de la dinastía de los Habsburgo.

En este orden de ideas, el reclamo de la minoría, dirigido a que se hiciera expresa mención al carácter justificado de la conducta tratándose de adultos que consienten y que no conviven dentro del seno familiar, es un esfuerzo por lograr que la justificación sea encauzada por los canales jurídicos, en lugar de reintroducir la moral de manera acrítica.

Precisamente, esta incapacidad de la mayoría para realizar un juicio de proporcionalidad en el caso concreto impide responder a las preguntas expuestas en el acápite anterior. Lo que no responde la Corte, y la minoría reclama, es

25. Pues ha reclamado un juicio de proporcionalidad. 
cómo pasar de lo factual a lo valorativo. Si bien de los hechos no se sigue necesariamente (Iógicamente) la exigencia de un comportamiento o una restricción a un derecho, una debida ponderación permite valorar la situación fáctica, justificar la necesidad de la restricción y, finalmente, validar su extensión. Al abdicar, la Corte termina por dar la razón a la minoría: se trata de una decisión que no está debidamente fundamentada. ${ }^{26}$

\section{Propuesta}

Las dificultades argumentativas de la Sentencia C-404 de 1998 de la Corte Constitucional se explican, como se ha expuesto, por la renuncia a ponderar y a realizar un juicio de proporcionalidad que le permita justificar que perseguir el fin moral de prohibición del incesto es un fin constitucional legítimo, y que la adopción de la restricción absoluta es una limitación proporcionada a la libertad.

Las dificultades parecen surgir del equivocado peso que la propia Corte da a su definición operativa de moralidad pública. Esta, en lugar de justificar la inclusión de la restricción basada en razones morales, puede entenderse de manera que articule un análisis jurídico sobre la admisibilidad de la restricción. En este orden de ideas, la legitimidad del fin (introducción de una restricción a un derecho con base en razones morales) se determina a partir de la satisfacción de la definición operativa de moralidad pública propuesta por la Corte. En otras palabras, será legítimo perseguir la positivización de un principio moral, por simples razones morales, si este satisface los requisitos de moralidad pública definidos por la Corte. Pero superado este primer paso, se requiere un juicio propio del derecho, a fin de vincular el principio moral a los estándares jurídicos.

Las dificultades para avanzar se encuentran en la misma definición operativa, que pareciera construir un juicio específico que introduce un juicio de necesidad y de indispensabilidad, lo que permitiría entender que el juicio de proporcionalidad se realiza al satisfacer los requisitos de la definición operativa.

Sin embargo, dicho problema se supera si se entiende, como se ha propuesto, que el juicio derivado de la definición operativa se limita al fin de la medida. ¿Cómo entonces entran en juego los criterios de necesidad y de indispensabilidad? ¿No constituyen, en la práctica, un juicio previo sobre la necesidad de la medida dentro de un juicio estándar de proporcionalidad?

En numerosas ocasiones la jurisprudencia ha aludido a que en algunos casos las restricciones a los derechos fundamentales deben perseguir fines imperiosos. Así, en Sentencia C-274 de 2013, la Corte Constitucional precisó

26. No sobra mencionar que el silencio frente a un argumento constituye una falta argumentativa. Sobre las reglas de la argumentación, y en particular de la argumentación jurídica ver Alexy (1989). 
que las limitaciones al principio de publicidad de la información pública se justifican cuando la reserva obedece a un "fin constitucionalmente legítimo, importante y hasta imperioso". En esta línea de razonamiento, el juicio de necesidad y de indispensabilidad entraría a configurar, para el caso de incorporación de un fin moral, el análisis de que la medida es imperiosa.

Así, el análisis de necesidad no se dirige a estudiar la relación entre el medio seleccionado $y$ el fin, sino a que el fin sea necesario. En el caso de la definición operativa analizada, necesaria "para armonizar proyectos individuales de vida" como se lee en la sentencia. Por su parte, el análisis de indispensabilidad es más problemático.

La Corte Constitucional, con posterioridad a la sentencia que se estudia, introdujo estos elementos en el llamado juicio integrado de igualdad, al distinguir entre los test débil, intermedio y estricto. ${ }^{27} \mathrm{El}$ criterio de indispensabilidad se ha referido a una gradación del juicio de necesidad. Así, se indica que "la diferencia de trato debe ser necesaria e indispensable $y$, ante la presencia de restricciones menos gravosas, la limitación quedaría sin respaldo constitucional" (CConst., C-093/2001, A. Martínez). Dado que el juicio de necesidad supone que la medida seleccionada es la menos gravosa, ¿cómo se gradúa dicho juicio a fin de incorporar la indispensabilidad? Una opción sería considerarla en sentido negativo. Esto es, que, sin ese elemento, resulta imposible (altamente imposible) la realización del objetivo de la regulación.

En este orden de ideas, el juicio de necesidad al que se refiere el juez constitucional adquiere pleno sentido, pues la introducción de la restricción (moral pública) se explica porque es requerida para articular los proyectos individuales de vida; es decir, el principio moral se convierte en base para que exista convivencia. Así mismo, el juicio de indispensabilidad permitiría verificar que operativamente el principio moral se inserta en los procesos de formación e incorporación de los valores de responsabilidad y solidaridad, sin los cuales es imposible la convivencia. En otras palabras, si y solo si se incorpora dicha regla moral, es posible asegurar la convivencia en términos compatibles con el orden constitucional.

En el caso de la prohibición del incesto, tal ejercicio podría ser como sigue. Se podría arribar a la conclusión de que satisface los criterios de moralidad pública en la medida en que la interdicción del interés sexual hacia los miembros de la familia permitiría consolidar un espacio social -la familia- libre de violencia (violencia derivada de exigir sexo por parte del poderoso) y formar los roles sobre los cuales se edificará una personalidad autónoma, respetuosa del otro (precisamente porque no violenta) y, de esta manera, alcanzar la solidaridad intrafamiliar.

27. Ver Sentencia C-093/2001 (M. P.: A. Martínez). 
La sanción penal al incesto aparece adecuada a este fin, en la medida en que se reconoce el principio de prevención general. ${ }^{28}$ La cuestión central tiene que ver con la proporcionalidad de la medida. Aunque parece evidente que las prácticas incestuosas dentro del seno familiar, aquellas entre padres e hijos y las que involucran menores de edad, tendrían efectos negativos para la realización del fin de consolidación de la familia en los términos descritos, ello no es claro en el caso de adultos - por ejemplo, hermanos- que deciden mantener estas relaciones por fuera del seno de la familia. En tal situación no es palpable cómo la realización de valores constitucionales -que es lo que justifica la positivización del principio moral- se ve afectada, pues el proceso formativo debió tener lugar mientras vivieran dentro del seno familiar. ${ }^{29}$ Una vez finalizada tal convivencia ¿cuál es el propósito de la prohibición? Mientras este punto no se resuelva, el costo para la libertad es enorme.

Por otra parte, esta solución parece dar razón a quienes asumen que la moral positivizada pierde su autonomía respecto del orden moral y queda sujeta a parámetros jurídicos. Empero, estas posturas omiten considerar la doble dimensión del continuum moral-derecho. Antes se señaló que en un plano el derecho termina por disolverse en la moral, mientras que en otro el camino es inverso. A fin de tomar en serio tanto a la moral como al derecho, no basta con negar el carácter jurídico a la regla extremadamente injusta. También ha de rechazarse la regla moral absolutamente incompatible con el orden jurídico. Claro, siempre y cuando este satisfaga criterios básicos de una moral justificada.

\section{RECAPITULACIÓN Y CONCLUSIONES}

A lo largo de este escrito se ha analizado la Sentencia C-404 de 1998 de la Corte Constitucional. El estudio de la sentencia permitió identificar tres escenarios argumentativos, cada uno de ellos con diversos problemas.

El primer escenario, dirigido a justificar la prohibición del incesto debido a su capacidad destructiva de la familia y la puesta en peligro del valor solidaridad, presenta problemas argumentativos, en particular por la incorporación de elementos retóricos, claramente dirigidos a persuadir, como es la referencia al horror de la malformación y al terror de la pérdida de la solidaridad.

El segundo escenario, donde se centra el interés de la sentencia, está dirigido a resolver la cuestión de la relación entre moral y derecho. Se mostró cómo el debate se dio en pla-

28. Punto que podría ser altamente discutible, pero que desborda los propósitos de este escrito. Un análisis interesante e ilustrativo sobre el debate en torno al principio de prevención general se encuentra en el artículo de Puig (1986), Función fundamentadora y función limitadora de la prevención general positiva.

29. Aquí claramente se distingue entre familia como lazos de afecto y los lazos de consanguinidad, del hecho de convivir dentro de la familia. 
nos distintos, pero no irreconciliables. La reconstrucción del debate permitió reformular los problemas iniciales de donde partieron las argumentaciones, hacia la cuestión de si la definición operativa de moralidad pública que construyó la Corte permite superar la acusación de que la apelación a la moral conduce a la selección subjetiva de moral. La conclusión es que efectivamente permite su superación, no porque ofrezca un criterio objetivo para identificar la moralidad pública, sino porque admite que existen diversas moralidades públicas que compiten, y que la cuestión constitucional se centra en establecer si aquella que desea abrazar el legislador es compatible o no con el orden constitucional.

Podría decirse que la Corte coloca en pie de igualdad el argumento moral y otros tipos de argumentos: estos son admisibles si son compatibles con la Constitución. Con ello, se admite, como se le atribuye al neoconstitucionalismo, que la Constitución encarna un orden de valores y que toda referencia extrajurídica ha de pasar por su tamiz, inclusive la moral. Por otra parte, se dan puntadas para superar la discusión sobre la conexión necesaria o contingente entre derecho y moral, dado que se sujeta el segundo al primero.

Ahora bien, se estableció que en términos justificatorios la Corte no logra demostrar que el principio moral de prohibición del incesto satisface las condiciones de su propia construc- ción. Es decir, no se demostró que satisfacía los requisitos definidos para ser una moralidad pública admisible constitucionalmente.

Ello se debe a que, lo que es tema del tercer escenario, la Corte abdica a realizar un juicio de ponderación y de proporcionalidad. La Corte termina por aceptar sin más el principio moral y las consecuencias definidas por el legislador.

Se planteó que es posible que se haya arribado a dicha solución debido a las dificultades propias de la definición operativa, que parecieran incluir elementos del juicio de proporcionalidad dentro del test que establece. Para superar esta dificultad se propuso que la definición operativa ha de obrar en el nivel del análisis del fin perseguido y que, tal y como está construida, contiene los elementos para verificar que se persigue un fin imperioso, el cual justificaría la restricción de un derecho fundamental por razones exclusivamente morales. Luego, el siguiente paso sería un juicio de proporcionalidad para establecer si la relación entre el medio y el fin es compatible con la Constitución.

Se concluye que, si bien la prohibición del incesto satisface los presupuestos de moralidad pública, la Corte Constitucional debió realizar un juicio de proporcionalidad a fin de establecer si la restricción absoluta resultaba admisible en todos los escenarios. Al no hacerlo, se hizo un injustificado sacrifico a la libertad. 
Referencias

1. Aguiló, J. (2008). Sobre derecho y argumentación. Palma, Mallorca: Lleonard Muntaner.

2. Alexy, R. (1989). Teoría de la argumentación jurídica. Madrid: Centro de Estudios Constitucionales.

3. Alexy, R. (1997). El concepto y la validez del derecho (Segunda ed.). (J. M. Seña, Trad.). Barcelona: Gedisa.

4. Alexy, R. (2001a). Teoría de los derechos fundamentales. Madrid: Centro de Estudios Políticos y Constitucionales.

5. Alexy, R. (2001b). Una defensa de la fórmula de Radbruch. Anuario da Facultade de Dereito da Universidade da Coruña, (5), 75-96. Obtenido de ruc.udc: http://ruc. udc.es/dspace/bitstream/2183/2109/1/ AD-5-4.pdf

6. Aristóteles. (1990). Retórica. (Q. Racionero, Trad.). Madrid: Gredos.

7. Comanducci, P. (2003). Formas de (neo) constitucionalismo:unanálisismetateórico. En M. Carbonell, Neoconstitucionalismo(s) (pp. 75-98). Madrid: Trotta.

8. Durkheim, É. (1999). Da divisão do trabalho social (Segunda ed.). (E. Bandâo, Trad.). Sâo Paulo: Martins Fontes.

9. Dworkin, R. (2011). Justice for hedgehogs. Cambridge, Massachusets; London, England: Harvard University Press.
10. Ferrajoli, L. (2011). Principia iuris. Teoría del derecho y de la democracia (Vol. 1. Teoría del derecho). Madrid: Trotta.

11. Ferrajoli, L., y Ruiz Manero, J. (2012). Dos modelos de constitucionalismo. Una conversación. Madrid: Trotta.

12. Habermas, J. (1996). Between facts and norms. Contributions to a discourse theory of law and democracy. (W. Rehg, Trad.). Cambridge: The MIT Press.

13. Habermas, J. (2005). Facticidad y validez. Sobre el derecho y el Estado democrático de derecho en términos de teoría del discurso. (Cuarta ed.). Madrid: Trotta.

14. Hart, H. (1992). El concepto de Derecho. Buenos Aires: Abeledo-Perrot.

15. Monereo Pérez, J. L. (2008). El pensamiento jurídico-político de Durkheim: solidaridad, anomia y derecho (II). Revista de derecho constitucional europeo, (10), 387-434. Obtenido de: dialnet.unirioja.es/descarga/ /3014022.pdf

16. Nino, C. (2014/1994). Derecho, moral y política. Buenos Aires: Siglo Veintiuno Editores.

17. Puig, M. (1986). Función fundamentadora y función limitadora de la prevención general positiva. Anuario de derecho penal y ciencias penales, (39(1)), 59-58. Obtenido de: dialnet.unirioja.es/descarga/ articulo/46280.pdf

18. Toulmin, S. (2007). Los usos de la argumentación. Barcelona: Península. 